\title{
Bioaccumulation modelling and sensitivity analysis for discovering key players in contaminated food webs: the case study of PCBs in the Adriatic Sea
}

\author{
Marianna Taffi ${ }^{\mathrm{a}, \mathrm{d}, *}$, Nicola Paoletti ${ }^{\mathrm{b}}$, Pietro Liò ${ }^{\mathrm{c}}$, Sandra Pucciarelli ${ }^{\mathrm{a}}$, Mauro Marini ${ }^{\mathrm{d}}$ \\ ${ }^{a}$ School of Biosciences and Veterinary Medicine, University of Camerino, Via Gentile III Da Varano 62032, Camerino, Italy \\ ${ }^{b}$ Department of Computer Science, University of Oxford, Parks road, Oxford OX1 3QD, United Kingdom \\ ${ }^{c}$ Computer Laboratory, University of Cambridge, 15 JJ Thomson Ave, Cambridge CB3 OFD, United Kingdom \\ ${ }^{d}$ National Research Council, Institute of Marine Science (ISMAR), Largo Fiera della Pesca 2, 60125 Ancona, Italy
}

\begin{abstract}
Modelling bioaccumulation processes at the food web level is the main step to analyse the effects of pollutants at the global ecosystem level. A crucial question is understanding which species play a key role in the trophic transfer of contaminants to disclose the contribution of feeding linkages and the importance of trophic dependencies in bioaccumulation dynamics. In this work we present a computational framework to model the bioaccumulation of organic chemicals in aquatic food webs, and to discover key species in polluted ecosystems. As a result, we reconstruct the first PCBs bioaccumulation model of the Adriatic food web, estimated after an extensive review of published concentration data. We define a novel index aimed to identify the key species in contaminated networks, Sensitivity Centrality, and based on sensitivity analysis. The index is computed from a dynamic ODE model parametrised from the estimated PCBs bioaccumulation model and compared with a set of established trophic indices of centrality. Results evidence the occurrence of PCBs biomagnification in the Adriatic food web, and highlight the dependence of bioaccumulation on trophic dynamics and external factors like fishing activity. We demonstrate the effectiveness of the introduced Sensitivity Centrality in identifying the set of species with the highest impact on the total contaminant flows and on the efficiency of contaminant transport within the food web.
\end{abstract}

Keywords: bioaccumulation modelling, ecological network analysis, Sensitivity Analysis, toxic keystoneness, Adriatic Sea, Polychlorinated Biphenyls, Linear Inverse Modelling

\section{Introduction}

A food web represents a comprehensive model to interpret the pattern of trophic connectedness in an ecosystem, where the biomass and energy flows are bound to a complex mixture of organic compounds. In the aquatic environment, persistent organic chemicals accumulate in the lipid tissue of organisms from dietary uptake and from exposure through water (Van der Oost et al., 2003). Bioccumulation phenomena occur when the concentration of a toxicant in marine biota is higher than in the surrounding environmental media (Mackay and Fraser, 2000). A variety of biological and chemical factors concerning both marine organisms and chemical compounds, combined with species feeding behaviour, can differently influence the patterns of contamination (Russell et al., 1999). Feeding relationships not only expose species to contamination processes but also become a critical medium of toxicant transfer, leading to biomagnification phenomena as the result of dietary uptake (Kelly et al., 2007, Lohmann et al., 2007).

Therefore, predator-prey interactions become central to characterize contamination patterns scaling from individuals to the ecosystem level, and to predict bioaccumulation effects on ecological networks (Rohr et al., 2006). Food web members exhibit

\footnotetext{
${ }^{*}$ Corresponding author

Email address: marianna.taffi@unicam.it (Marianna Taffi)
}

different ecological responses to accumulated concentrations of chemicals in function of their abundance, trophic position, feeding connections, and role in maintaining ecosystem functions (Ruus et al., 2002, Walters et al., 2008). As a consequence, the contribution of trophic connections in the contamination pathways cannot be considered equal for all species. Despite the trophic role of keystone species is well-established in ecology, the crucial question of which species play a central role in the trophic transfer of contaminants remains poorly understood.

In this work we present a computational framework for bioaccumulation modelling and for analysing the trophic role of species in contaminated food webs. We focus on foodweb bioaccumulation models, a class of ecological networks that represent and quantify the contaminant transfer between species by following the underlying feeding links. The bioaccumulation network is estimated from biomass and contaminant concentration data by using Linear Inverse Modelling (LIM) (Vézina and Platt, 1988, van Oevelen et al., 2010), a technique that supports incomplete and uncertain input data. In order to complete our framework, we employ ecological network analysis tools to identify the toxic keystones. Specifically, we apply indices of ecological centrality, typically used for trophic conservation purposes (Jordán, 2009), to provide indicators of species' importance in the bioaccumulation context. To this aim, we also introduce Sensitivity Centrality (SC), a novel in- 
dex based on the sensitivity analysis of dynamic models, and suitable to express information on the temporal patterns of contamination. In our case, SC is computed from a multi-species Lotka-Volterra ODE model derived from the estimated bioaccumulation network.

We apply the framework to the case study of polychrorinated biphenyls (PCBs) bioaccumulation in the Adriatic food web. In the last decades this region has become of great interest from an ecotoxicological viewpoint, since it has been subject to dramatic changes in marine resources driven by anthropogenic and environmental perturbations. PCBs are industrial chemicals liable to contamination problems in the aquatic environments, and among other regions, they have been detected both in abiotic compartments and living organisms in the Adriatic sea (Picer, 2000). This class of persistent organic pollutants consists of 209 different congeners and are chemically characterised by high environmental persistence, being practically insoluble in water. Moreover for their liphophilic properties, PCBs readily dissolve in fats and lipids of aquatic organisms leading to bioaccumulation phenomena in species.

In our study, input biomass data is compiled from a complete and validated trophic model of the Adriatic food web (Coll et al., 2007) and we collect PCBs concentration data after an extensive review of specific experimental literature. As a result, we obtain the first food-web bioaccumulation model of PCBs in the Adriatic ecosystem, where missing concentration data is estimated by combining LIM with stochastic sampling techniques. Finally, we analyse toxic keystones and evaluate the newly introduced Sensitivity Centrality index on the obtained bioaccumulation network.

LIM-based methods have been extensively applied to the reconstruction of food webs from empirical data. Ecopath (Christensen and Walters, 2004) is one of the most established and used LIM tools, and includes the Ecotracer routine for bioaccumulation analysis. In this work we choose the $\mathrm{R}$ package LIM (van Oevelen et al., 2010) because it supports custom equations and multiple flow currencies (both biomass and PCBs), a crucial feature of our framework. Other LIM approaches for bioaccumulation modelling include Toxlim (Laender et al., 2009), a R-package implementing the OMEGA model (Hendriks et al., 2001).

A LIM model of the Venice lagoon food web is developed by Brigolin et al. (2011) to study the temporal evolution of ecosystem productivity and fishing. The estimation is based on randomly perturbing input data to avoid the bias of constraints on the obtained solutions. Our LIM trophic model is compiled taking input data from the work by Coll et al. (2007), where the Northern and Central Adriatic food web is reconstructed using Ecopath. In the estimation of the bioaccumulation network, we consider a different approach in order to account for uncertainty, based on the Markov Chain Monte Carlo (MCMC) sampling of the solution space.

Models for assessing and predicting PCBs bioaccumulation have been proposed for two main Adriatic areas: the Venice lagoon (Losso and Ghirardini, 2010, Dalla Valle et al., 2005, 2007) and the Po river delta (Spillman et al., 2007, 2008). These works investigate the contaminant fate and distribution in spe- cific habitats, and the analysis is limited to the lower trophic levels of the food web.

In the trophic context, keystone species are typically studied by applying ecological network indices to food web models. Indicators based on the Mixed Trophic Impact analysis (Ulanowicz and Puccia, 1990) give a quantitative characterization of keystoneness (Power et al., 1996, Ulanowicz, 2004, Libralato et al., 2006). Topological centrality indices provide instead qualitative descriptors of trophic importance (Jordán, 2009, Estrada, 2007, Bauer et al., 2010). In our framework, these indices are applied to identify key players in a contaminated food web and to this aim, we propose a novel formulation of keystoneness based on sensitivity analysis.

Ciavatta et al. (2009) employ Monte Carlo-based global sensitivity analysis to study the relevance of chemical and ecological parameters in the computed concentration values of two species in the Venice lagoon food web. Similar applications of sensitivity analysis in bioaccumulation modelling are found in Carrer et al. (2000), Lamon et al. (2012), De Laender et al. (2010). In our work, we consider local sensitivity for the analysis of toxic keystones, by computing it from an ODE model parametrised with the bioaccumulation network outputs.

Within the proposed framework, our aim is twofold:

1. Reconstruct the first PCBs bioaccumulation model for the Adriatic food web, by providing a review of experimental concentration data and estimating missing concentrations.

2. Investigate the role of keystone species in the contaminant transfer through food webs by defining and evaluating a new index of species centrality.

\section{Materials and Methods}

Figure 1 illustrates the modelling and analysis steps implemented in our framework for the study of PCBs bioaccumulation in the Adriatic food web. First, we estimate the trophic and the bioaccumulation network using biomass and PCBs concentrations data, respectively. Second, we derive a dynamic ODEbased model from the obtained static bioaccumulation network. Last, we introduce a new index, Sensitivity Centrality, and evaluate its effectiveness through the comparison with a set of established centrality indices with respect to global network indices.

\subsection{Adriatic Sea ecosystem}

This study focuses on the Adriatic Sea, a distinct sub-region of the Mediterranean Sea, considered a critical water body due to the presence of intensive fishing effort (Coll et al., 2009) and river inputs flowing into the basin (Degobbis et al., 2000), which threatens the marine biological diversity (Coll et al., 2010, Penna et al., 2004). Within the Adriatic region, the freshwater discharge of the Po river exerts a strong effect on the chemical and physical dynamics of the coastal ecosystem (Marini et al., 2002). The river crosses a wide industrial and agricultural area and largely contributes to the nutrient and chemical loads flushed into the sea (Calamari et al., 2003), with a mean rate of discharge of $1500 \mathrm{~m}^{3} \cdot \mathrm{s}^{-1}$ (Campanelli et al., 


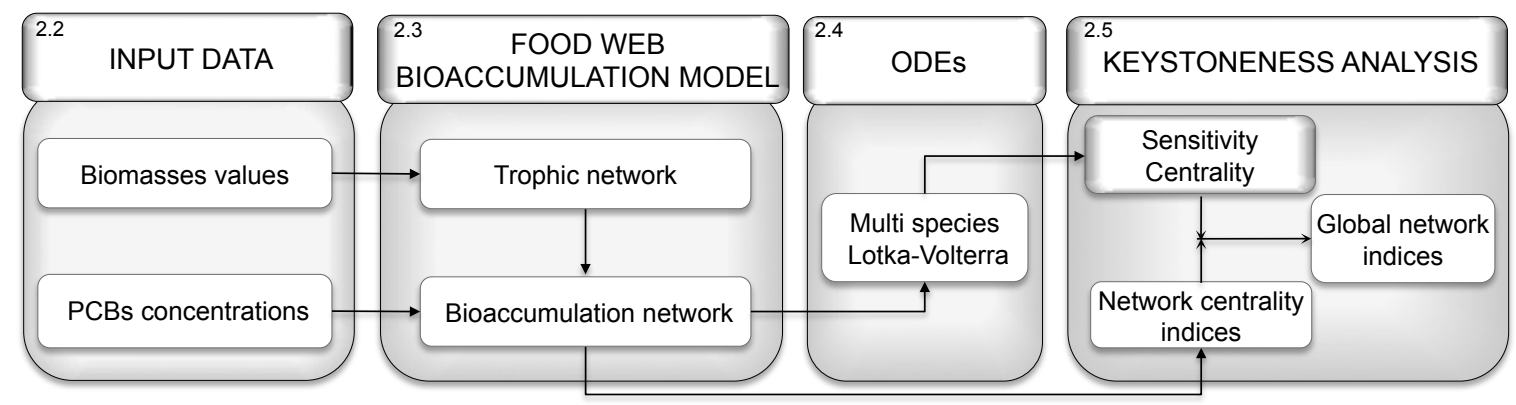

Figure 1: Bioaccumulation analysis framework. Workflow of performed analyses and corresponding section numbers

2011). The southeaster part of the Adriatic Basin is equally affected by riverine inputs, representing besides the unique canal to the open Ionian Sea (Marini et al., 2010). As a result, in the last decades a variety of organic chemicals have been detected in this region, with significant concentrations both in species and environmental compartments (Marini et al., 2012, Bellucci et al., 2002, Horvat et al., 1999, Kannan et al., 2002).

\subsection{Input data}

The ecological classification of Adriatic species and input data used in the estimation of the trophic model are obtained from the information collected in (Coll et al., 2007), a computational study aimed at evaluating fishing impacts on the Adriatic ecosystem during the 1990s. For each functional group we consider the following data (see Table A.5 in the Appendix): biomass $B$, production rate $P$, consumption rate $Q$, and fishing, which consists of landing (Lan) and discard (Dis) fractions. Biomass flows are expressed in $t \cdot \mathrm{km}^{-2} \cdot \mathrm{yr}^{-1}$ wet weight organic matter and biomass in $t \cdot \mathrm{km}^{-1}$. Diet composition is illustrated in Fig. A.7 (a) of the supplementary materials.

In our analysis, input parameters of the bioaccumulation model have been compiled after an extensive literature review of published PCBs concentrations data, collected over the period 1994-2002 on species throughout the Adriatic region. All data sources report both the single value and the sum of all PCBs congeners detected in the edible part and muscle tissue of sampled species, expressed in $n g \cdot g^{-1}$ and $p g \cdot g^{-1}$ wet weight. In this work we consider the sum of PCBs congeners, reported in Table 1. For groups with no concentration data available, we take published PCBs values for comparable species by following the taxonomic classification in WoRMS database ${ }^{1}$. A detailed list of all data sources is available in Table A.6 of the supplement. Units of the bioaccumulation model are expressed in $n g \cdot g^{-1}$ wet weight for concentrations, and $n g \cdot g^{-1} \cdot t \cdot \mathrm{km}^{-2} \cdot \mathrm{y}^{-1}$ for contaminant flows.

\subsection{Food web bioaccumulation model}

We define a mechanistic model of PCBs bioaccumulation, where contaminant pathways are coupled to trophic interactions. Flow rates quantify the intensity at which the medium

\footnotetext{
${ }^{1}$ http://www.marinespecies.org/
}

(i.e. biomass or contaminant) is transferred from the source (the prey) to the target (the predator). Flows are estimated under mass-balance conditions, i.e. the total inflows of a group must equal the total outflows, and are computed from input values of concentration and biomass. External unbalanced compartments are also included, to model potentially unlimited exogenous imports and exports.

The conceptual model of the bioaccumulation network is illustrated in Figure 2. Biomass and contaminant flows from a prey $i$ to a predator $j$ are denoted with $b_{i \rightarrow j}$ and $c_{i \rightarrow j}$, respectively. The flows included are: Consumption $\left(b_{j \rightarrow i}\right)$ and contaminant uptake $\left(c_{j \rightarrow i}\right)$ from a prey $j$. Predation $\left(b_{i \rightarrow k}\right)$ and contaminant loss $\left(c_{i \rightarrow k}\right)$ due to consumption by a predator $k$. External inputs from Import $\left(b_{\operatorname{Import}} \mapsto_{i}\right.$ and $\left.c_{\text {Import }}\right)$, used to model generic inflows like immigration. Contaminant uptake from water $\left(c_{\text {Water }} i\right)$, which clearly does not involve a corresponding biomass transfer. External outputs to Export $\left(b_{i} \rightarrow\right.$ Export and $c_{i} \rightarrow$ Export $)$, used to model generic outflows like emigration. Respiration flows ( $b_{i} \rightarrow$ Respiration and $c_{i} \rightarrow$ Respiration $)$ and flows to natural detritus ( $b_{i \rightarrow \text { Detritus }}$ and $c_{i} \rightarrow$ Detritus), constituting together the unassimilated portion of the biomass ingested by $i$. Outflows due to fishing activity, that can exit the food web to the landings ( $b_{i} \rightarrow$ Landing and $c_{i} \rightarrow$ Landing $)$, or enter back the biomass cycle through the discard group ( $b_{i \rightarrow \text { Discard }}$ and $c_{i} \rightarrow$ Discard $)$.

On the other hand, detritus and planktonic groups are assumed to be in instant equilibrium with the water phase. Following Hendriks et al. (2001), Laender et al. (2009), their concentration $C_{i}$ is determined only by the concentration in water, $C_{\text {water }}$ (measured in $\mu g / L$ ), and computed as:

$$
C_{i}=C_{\text {water }} \cdot O C_{i} \cdot K_{O C}, \quad K_{O C}=k_{O C / O W} \cdot K_{O W}
$$

where $K_{O C}$ is the organic carbon-water partition ratio; $K_{O W}$ is the octanol-water partition coefficient, which measures the ratio of contaminant solubility and its value differs among PCB congeners. Since in the model the sum of congeners is considered, we set $K_{O W}=10^{6}$, given that the $\log K_{O W}$ of PCBs varies between 5 and 7 (Walters et al., 2011). The other parameters are $O C_{i}=0.028$ and $k_{O C / O W}=0.41$ (Laender et al., 2009).

\subsubsection{Estimation with Linear Inverse Modelling}

The trophic and bioaccumulation networks are estimated from biomass and concentration data through Linear Inverse 
Table 1: Input PCBs concentration data $\left(n g \cdot g^{-1}\right)$ by functional group, with corresponding species and references. In order to account for multiple data source, we derive concentration ranges instead of single values.

\begin{tabular}{|c|c|c|c|}
\hline Id.Group & $\sum \mathrm{PCB}(\min -\max )$ & Species & Sources \\
\hline \multicolumn{4}{|l|}{ 1.Phytoplankton } \\
\hline \multicolumn{4}{|l|}{ 2.Micro and mesozooplankton } \\
\hline \multicolumn{4}{|l|}{ 3.Macrozooplankton } \\
\hline \multicolumn{4}{|l|}{ 4.Jellyfish } \\
\hline \multicolumn{4}{|l|}{ 5.Suprabenthos } \\
\hline \multicolumn{4}{|l|}{ 6.Polychaetes } \\
\hline \multirow[t]{2}{*}{ 7.Commercial benthic invertebrates } & $1.24-20.29$ & M. galloprovincialis & (Perugini et al., 2004) \\
\hline & & M. galloprovincialis, C. gallina & (Bayarri et al., 2001) \\
\hline 8.Benthic Invertebrates & & $\begin{array}{l}\text { C. gallina, A. tubercolata, E. siliqua, } \\
\text { M. galloprovincialis }\end{array}$ & (Marcotrigiano and Storelli, 2003) \\
\hline \multirow[t]{2}{*}{ 9.Shrimps } & $0.346-11.61$ & P. longirostris, A. antennatus & (Marcotrigiano and Storelli, 2003) \\
\hline & & $\begin{array}{l}\text { A. antennatus, } P \text {. longirostris, } P \text {. } \\
\text { martia }\end{array}$ & (Storelli et al., 2003) \\
\hline 10.Norway lobster & $0.2-10.63$ & N. norvegicus & $\begin{array}{l}\text { (Bayarri et al., 2001, Perugini et al., } \\
\text { 2004, Storelli et al., 2003) }\end{array}$ \\
\hline 11.Mantis shrimp & $2.64-11.61$ & S. mantis & (Marcotrigiano and Storelli, 2003) \\
\hline \multicolumn{4}{|l|}{ 12.Crabs } \\
\hline \multirow[t]{2}{*}{ 13.Benthic cephalopods } & $0.31-6.7$ & T. sagittatus, S. officinalis & (Perugini et al., 2004) \\
\hline & & O. salutii & (Marcotrigiano and Storelli, 2003) \\
\hline \multirow[t]{2}{*}{ 14.Squids } & $9.53-37.7$ & L. vulgaris & (Bayarri et al., 2001) \\
\hline & & I. coindetii & (Marcotrigiano and Storelli, 2003) \\
\hline 15.Hake 1 & $3.183-31.93$ & M. merluccius & $\begin{array}{l}\text { (Storelli et al., 2003, Marcotrigiano } \\
\text { and Storelli, 2003) }\end{array}$ \\
\hline 16.Hake 2 & & $"$ & $"$ \\
\hline \multicolumn{4}{|l|}{ 17.Other gadiformes } \\
\hline \multicolumn{4}{|l|}{ 18.Red mullets } \\
\hline 19.Conger eel & $22.424-104$ & C. conger & (Storelli et al., 2003, 2007) \\
\hline 20.Anglerfish & $0.2-$ & L. boudegassa & (Storelli et al., 2003) \\
\hline \multicolumn{4}{|l|}{ 21.Flatfish } \\
\hline \multicolumn{4}{|l|}{ 22. Turbot and brill } \\
\hline 23.Demersal sharks & $2-42$ & C. granolousus, S. blainvillei & (Storelli and Marcotrigiano, 2001) \\
\hline 24.Demersal skates & $0.45-$ & $\begin{array}{l}\text { R. miraletus, } R . \text { clavata, } R \text {. oxyrhin- } \\
\text { cus }\end{array}$ & (Storelli et al., 2003) \\
\hline 25.Demersal fish 1 & 6.687 & S. flexuosa, H. dactyloptereus & (Storelli et al., 2003) \\
\hline 26.Demersal fish 2 & " & " & $"$ \\
\hline 27.Bentopelagic fish & $"$ & " & " \\
\hline 28.European Anchovy & $1.22-62.7$ & E. encrasicolus & $\begin{array}{l}\text { (Perugini et al., 2004, Bayarri et al., } \\
\text { 2001) }\end{array}$ \\
\hline 29.European Pilchard & $5.327-26.25$ & S. pilchardus & $\begin{array}{l}\text { (Perugini et al., 2004, Storelli et al., } \\
\text { 2003) }\end{array}$ \\
\hline 30.Small Pelagic Fish & $4.54-31.9$ & S. aurita & (Marcotrigiano and Storelli, 2003) \\
\hline & & S. maris, A. rochei & (Storelli et al., 2003) \\
\hline 31.Horse Mackarel & 6.761 & T. trachurus & (Storelli et al., 2003) \\
\hline 32.Mackarel & $0.95-80.6$ & S. scombrus & $\begin{array}{l}\text { (Perugini et al., 2004, Bayarri et al., } \\
\text { 2001) }\end{array}$ \\
\hline \multicolumn{4}{|l|}{ 33.Atlantic bonito } \\
\hline \multicolumn{4}{|l|}{ 34.Large Pelagic Fish } \\
\hline \multicolumn{4}{|l|}{ 35.Dolphins } \\
\hline 36.Loggerhead turtle & $0.63-23.49$ & C. caretta & $\begin{array}{l}\text { (Storelli et al., 2007, Corsolini et al., } \\
2000)\end{array}$ \\
\hline \multicolumn{4}{|l|}{ 37.Sea birds } \\
\hline \multicolumn{4}{|l|}{ 38.Discard } \\
\hline 39.Detritus & & & \\
\hline
\end{tabular}




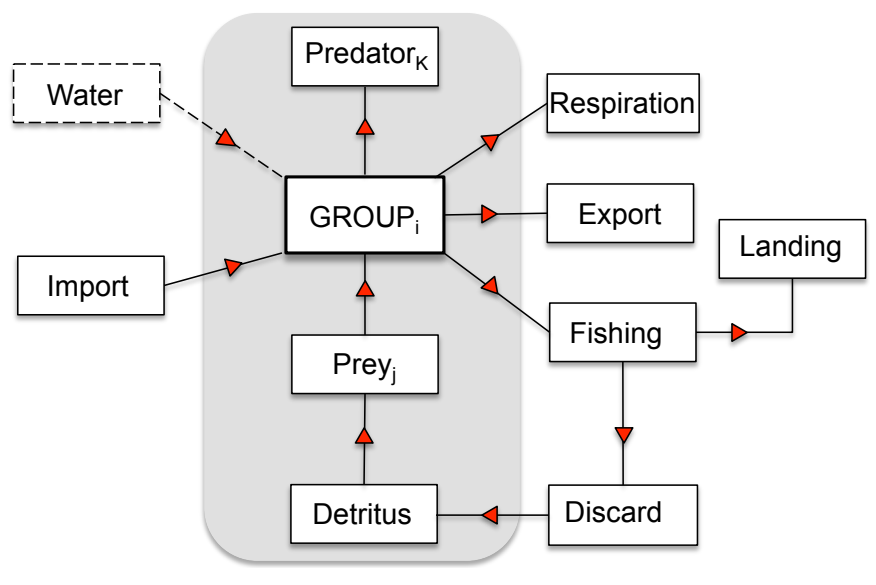

Figure 2: Conceptual bioaccumulation model. Black lines represent feeding linkages and red triangles specify the direction of trophic and contaminant flows. Mass-balanced groups are enclosed in the gray box $(i, j, k$ refer to generic groups). External comparments (not mass-balanced) are depicted outside. The contaminant uptake from the water compartment (dashed) occurs without trophic interactions.

Modelling (LIM) (van Oevelen et al., 2010), used to quantify the unknown flow rates by solving a system of linear constraints.

We first reconstruct the trophic network by solving the constraints in Table 2. Then, the computed biomass flows are used as input parameters for the estimation of the PCBs bioaccumulation network, according to the linear inverse model in Table 3.

The trophic LIM was formulated as an approximate problem, i.e. including a set of equations $A \cdot x \simeq b$ that are not solved exactly, but in a least square sense. $\|A \cdot x-b\|^{2}$ is minimized and solutions are accepted up to a fixed tolerance value $\epsilon$, by imposing the constraint $\|A \cdot x-b\|^{2} \leq \epsilon(\|$.$\| is the Euclidean norm).$ In the model, only diet and fishing constraints are solved approximately, with $\epsilon=10^{-8}$. The corresponding exact problem resulted in an empty solution space, due to the many constraints generated from the available input data.

On the other hand, the exact bioaccumulation LIM yields a non-empty solution space, and thus multiple admissible values. This is explained by the partial availability of PCBs concentration data. In this case, we derive a statistically well-founded solution through Markov Chain Monte Carlo (MCMC) sampling of the solution space and by taking the mean of the sampled values. Note indeed that the mean of valid solutions to a linear system is in turn a valid solution to the system (van Oevelen et al., 2010).

\subsection{Derivation of ODE Model}

From the network estimation results we define a differential equation-based bioaccumulation model to analyse the dynamics of contaminant diffusion. In this work, the model is mainly used to compute the Sensitivity Centrality index, presented in Section 2.5.

We first derive a multi-species Lotka-Volterra ODE system that describes the temporal changes in species biomass. Then, the bioaccumulation model is obtained by extending the LotkaVolterra system with parameters from the estimated PCBs bioaccumulation network. The resulting differential equations describe the change rate of bioconcentrations, for all groups $i$ :

$$
\dot{C}_{i}(t)=w_{i} \cdot C_{\text {water }}+g_{i} \cdot C_{i}(t)+\sum_{j}\left(\frac{b_{j \rightarrow i} \cdot C_{j}(t)-b_{i \rightarrow j} \cdot C_{i}(t)}{B_{i}}\right)
$$

where $C_{i}(t)$ is the concentration in $i$ at time $t ; C_{\text {water }}$ is assumed constant; $w_{i}$ is the uptake rate from water by group $i ; B_{i}$ is the biomass of $i$; and $g_{i}$ is the growth rate of $i$, computed as the sum of the exogenous inflows and outflow of biomass (diet flows excluded), over the estimated biomass:

$$
g_{i}=\frac{\sum_{j} b_{j \rightarrow i}-\sum_{j} b_{i \rightarrow j}}{B_{i}}
$$

where $j$ ranges among the external groups. Details on the derivation of the bioaccumulation ODEs from the trophic Lotka-Volverra model are provided in Appendix A.1.

\subsection{Sensitivity-based Keystoneness Analysis}

Indices of species centrality in food webs are typically employed in trophic analysis for conservation purposes. Here, we apply these notions to the study of toxic keystones, i.e. species with a prominent role in the trophic transfer of a pollutant through the food web. We introduce a novel index based on the sensitivity analysis of ODE models, Sensitivity Centrality $(S C)$, in order to express dynamic aspects of bioaccumulation phenomena in the analysis of keystone species. In our study, we consider the ODE model in Section 2.4. SC is able to provide an intuitive characterization of centrality in a contaminated ecosystem: a keystone species is such that a perturbation of its concentration has a high impact on the total concentration of the food web.

Sensitivity Analysis (SA) (Brun et al., 2001, Soetaert and Petzoldt, 2010) computes the variation of model outputs with respect to variations of model inputs in order to evaluate how sensitive or robust the system is to perturbations. Specifically, $\mathrm{SC}$ is based on local sensitivity, where infinitesimal changes of model parameters are considered.

The Sensitivity Centrality of a group $i$ at time $t, S C_{i}(t)$ quantifies the variation of the total contaminant concentration in the food web at time $t, C_{t o t}(t)$, at infinitesimal variations of the initial concentration in group $i, C_{i}(0)$ :

$$
S C_{i}(t)=\left|\frac{\partial C_{t o t}(t)}{\partial C_{i}(0)} \cdot \frac{C_{i}(0)}{C_{t o t}(t)}\right| .
$$

We take the absolute value of the sensitivity in order to give the same importance to both large positive and negative effects. The term $\frac{C_{i}(0)}{C_{t o t}(t)}$ serves as a weighting factor.

\subsubsection{Network centrality indices}

In order to evaluate the introduced Sensitivity Centrality, we compare its performance with respect to other well-established indices of keystoneness, that are computed from the static bioaccumulation network. The considered indices are:

Keystoneness (KS) (Libralato et al., 2006), a quantitative descriptor of species' importance, weighted by their contribution 
Table 2: Linear Inverse Model for the estimation of biomass flows of a functional group $i$. Approximate equations are solved with a least square approach.

Mass balances: $\quad \sum_{j} b_{j \rightarrow i}-\sum_{j} b_{i \rightarrow j}=0$

The difference between inflows and outflows within group $i$ is zero; $j$ ranges among groups and externals.

Ingestion $^{1}: \quad I_{i}=\sum_{j} b_{j \rightarrow i}=B_{i} \cdot Q_{i}$

The total ingestion $I_{i}$, i.e. the sum of all the consumption flows, equals the product of biomass $B_{i}$ and consumption rate $Q_{i}$. $j$ is a functional group. Ingestion constraints are not included for detritus and phytoplankton.

Unassimilated Food: $\quad b_{i \rightarrow \text { Respiration }}+b_{i \rightarrow \text { Detritus }}=I_{i} \cdot\left(1-g_{i}\right)$

Respiration flows and flows to detritus are a fraction of the total ingestion and accounts for the proportion of food that is not converted into biomass. $g_{i}=\frac{P_{i}}{Q_{i}}$ is the gross food conversion efficiency (Christensen and Walters, 2004).

Respiration-assimilation: $\quad b_{i \rightarrow \text { Respiration }} \leq I_{i} \cdot g_{i}$

The ratio respiration/assimilation has to be lower than one to have realistic estimates (Coll et al., 2007).

$\operatorname{Diet}^{1}: \quad b_{i \rightarrow j} \simeq I_{j} \cdot D_{i j}$.

The biomass flow from prey $i$ to predator $j$ is the fraction of the total ingestion of $j$ coming from $i$. $D$ is the diet composition matrix, reported in Fig. A.7 (a) of the supplementary materials.

Fishing: $\quad b_{i \rightarrow \text { Landing }} \simeq \operatorname{Lan}_{i}$ and $b_{i \rightarrow \text { Discard }} \simeq$ Dis $_{i}$.

Input data on fishing activity $\left(\operatorname{Lan}_{i}\right.$ and $\left.D i s_{i}\right)$ is used to constrain the exports to landings and discards.

Non-negativity of flows: $\quad b \geq 0$

${ }^{1}$ For species with uncertain input biomass and diet data, appropriate inequalities are set.

Table 3: Linear Inverse Model for the estimation of the PCBs concentration of a functional group $i$. Concentrations in detritus and planktonic groups are computed differently (see Eq. 2.1)

Mass balances: $\quad \sum_{j} c_{j \rightarrow i}-\sum_{j} c_{i \rightarrow j}=0$

Concentrations are estimated under mass-balance assumption. $j$ ranges among functional groups and externals.

Concentration data: $\quad C_{i} \bowtie k$

$k$ is an input PCBs value that constrains the contaminant concentration $C_{i}$, with $\bowtie \in\{=, \leq, \geq\}$. Note that the same group can have associated arbitrarily many such constraints.

Uptake/losses from food: $c_{j \rightarrow i}=b_{j \rightarrow i} \cdot C_{j}$

The trophic transfer of contaminant from group $j$ to $i$ is the product of the corresponding biomass flow $b_{j \rightarrow i}$ and the concentration in $j$. It describes the PCBs uptake of predator $i$ from prey $j$, and the PCBs removal from prey $j$ due to consumption by $i$. The equation also characterizes the PCBs losses from $j$ to the externals, if $i \in\{$ Export, Respiration, Landing .

Uptake from generic imports: $\quad c_{\mathrm{Import} \rightarrow i}=b_{\mathrm{Import} \rightarrow i} \cdot C_{i}$

The PCBs concentration in the biomass imported into group $i$ is assumed to be the same as in $i$.

Uptake from water: $\quad c_{\text {Water } \rightarrow i}=w_{i} \cdot C_{\text {Water }}$

$w_{i}$ is the uptake rate of $i$ from water-borne contaminant and $C_{\text {Water }}$ is the contaminant concentration in water ${ }^{1}$. $w_{i}$ is assumed null for compartments in rapid equilibrium with the water phase.

\footnotetext{
Non-negativity of concentrations: $C_{i} \geq 0$

${ }^{1}$ If $C_{\text {water }}$ is unknown, the constraint becomes non linear and $w_{i}$ cannot be directly estimated. In that case, $c$ Water $\rightarrow i$ is estimated as a single variable.
} 
in terms of contaminant concentration:

$$
K S_{i}=\log \left(\epsilon_{i} \cdot\left(1-p_{i}\right)\right), \quad p_{i}=\frac{C_{i}}{\sum_{j} C_{j}}, \quad \epsilon_{i}=\sqrt{\sum_{j \neq i} M_{i j}^{2}}
$$

where $p_{i}$ is the contribution of group $i$ in the total concentration of the food web; and $\epsilon_{i}$ is the so-called overall effect of $i$, i.e. the sum of the indirect trophic impacts of $i$ on all the other species. $M_{i j}$ represents the contaminant variation in a group $j$ at infinitesimal increases of the contaminant in $i$, and is calculated through the Mixed Trophic Impact analysis (Ulanowicz and Puccia, 1990).

Flow Betweenness Centrality (FBC) (Freeman et al., 1991), a qualitative index expressing the topological importance of a group in maintaining the flows within the food web:

$$
F B C_{i}=\sum_{j \neq k, j \neq i, k \neq i}\left(\max _{G} c_{j} \rightarrow k-\max _{G \backslash i} c_{j} \rightarrow k\right)
$$

where $\max _{G} c_{j \rightarrow k}$ is the maximum contaminant flow between groups $j$ and $k$ in the food web $G$, and $\max _{G \backslash i} c_{j \rightarrow k}$ is the maximum flow when group $i$ is excluded from $G$.

\subsubsection{Global indices}

Global network indices are used to derive descriptors of the structure and properties of the whole ecosystem (Kones et al., 2009). They are applied in this case to the study of contaminated food webs in order to analyse bioaccumulation phenomena at the ecosystem level. By definition, a species plays a key role in its ecosystem if its extinction (or perturbation) has a large impact on global ecosystem functions.

Following Estrada (2007), Allesina and Pascual (2009), we employ global indices to compare the introduced keystoneness indices. In this analysis, we simulate sequences of extinctions performed in decreasing order of importance, as ranked by each index. Then, a keystoneness index is considered good when the associated extinction sequence produces a substantial disruption in the global ecosystem properties of interest. The global indices analysed are:

Total system throughflow (TST). It describes the total ecosystem activity as the sum of outflows (exports included) of all groups:

$$
T S T=\sum_{i} \sum_{j} c_{i}{ }_{j}
$$

Average path length (APL). It computes the average number of groups that each inflow passes through and thus, it measures the efficiency of contaminant transport pathways:

$$
A P L=\frac{T S T}{\sum_{i} \sum_{j \in E x t} c_{i j j}}
$$

where $E x t=\{$ Respiration, Export, Landing $\}$ is the set of external export compartments.

Link density ( $L D)$. It expresses the average number of links per species, providing a structural descriptor of the food web:

$$
L D=\frac{\sum_{i} \sum_{j}\left(c_{i} \rightarrow_{j}>0\right)}{n}
$$

where $n$ is the number of groups in the food network.

\section{Results and Discussion}

\subsection{Trophic and Bioaccumulation Network}

Results of the estimated Adriatic trophic and bioaccumulation networks are reported in Table 4 and graphically represented in Figure 3.

The analysis of the biomass network shows that groups occupying lower trophic positions are the most predominant in terms of biomass and flows. As visible in Fig. 3 (a), biomass values and trophic levels are negatively correlated. The only exception is the Discard group, which accounts for the discarded catches that enter back the food web. Discard is considered in this model as a detritus, and thus has a trophic level (TL) of 1 . However, it clearly possesses a much lower biomass than the natural detritus (group Detritus) and primary producers (group Phytoplankton). We report that our quantitative estimations agree with the original work by Coll et al. (2007), which confirms the consistency of our trophic model.

PCBs Bioaccumulation Analysis. On the contrary, PCBs bioaccumulation values tend to increase at higher trophic levels. Thus, a phenomenon of biomagnification is detected, as visible in the network plot (Fig. 3 (b)). Estimated PCBs values in top predators $(T L \geq 4)$ are: Large Pelagic Fish (70.491), Demersal skates (54.833), Turbot and brill (54.746), Dolphins (54.048), Anglerfish (53.808), and Atlantic bonito (52.704). Note that, Large Pelagic Fish (Tuna and Swordfish) shows by far the highest value, due to the concentration in groups composing its diet (mainly European Anchovy and Squids).

Moreover, the quality of input data (reported in Table 1) also influences estimated values. Specifically, the concentration in some top predators (Squids, Hake 2 and Demersal Sharks) is limited since their valid PCBs values are constrained with low upper bounds. On the contrary, high or infinite upper bounds yield high concentration values also for groups at $\mathrm{TL}=3$, like in Demersal fish 2, Flatfish, Bentopelagic fish and Mackarel. This is related to the fact that we use a stochastic search algorithm to solve the corresponding LIM problem, also implying that less constrained variables have higher variability (see standard deviation in Table 4).

Fishing effects on bioaccumulation. Fishing activity represents quantitatively a biomass loss and therefore a contaminant removal from the food web. In our model, relatively low PCBs values are detected for overexploited groups, i.e. where fishing rates exceed biomass. For instance, Crabs, Other gadiformes and Red mullets show concentrations $\left(<1 n g \cdot g^{-1}\right)$ substantially lower than those in species belonging to the same TL, but not affected by fishing pressure. A similar tendency is observed for Conger eel whose resulting concentration is close to the lower 


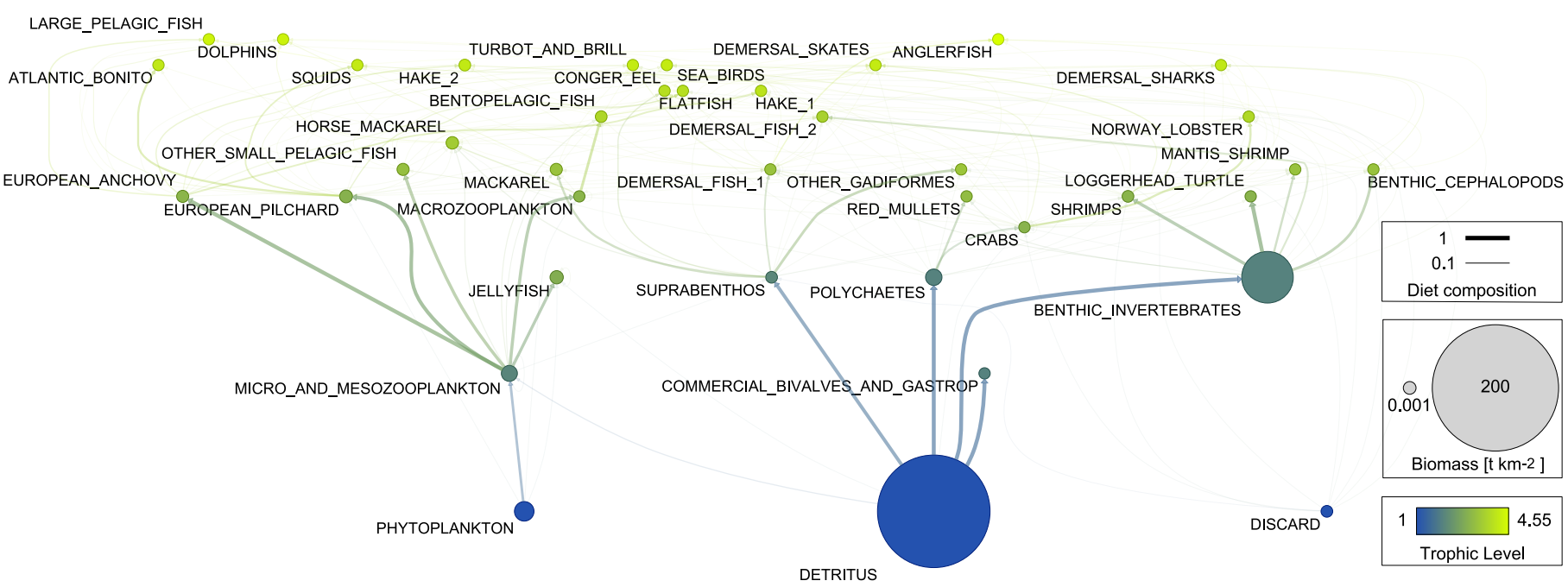

(a) Biomass network

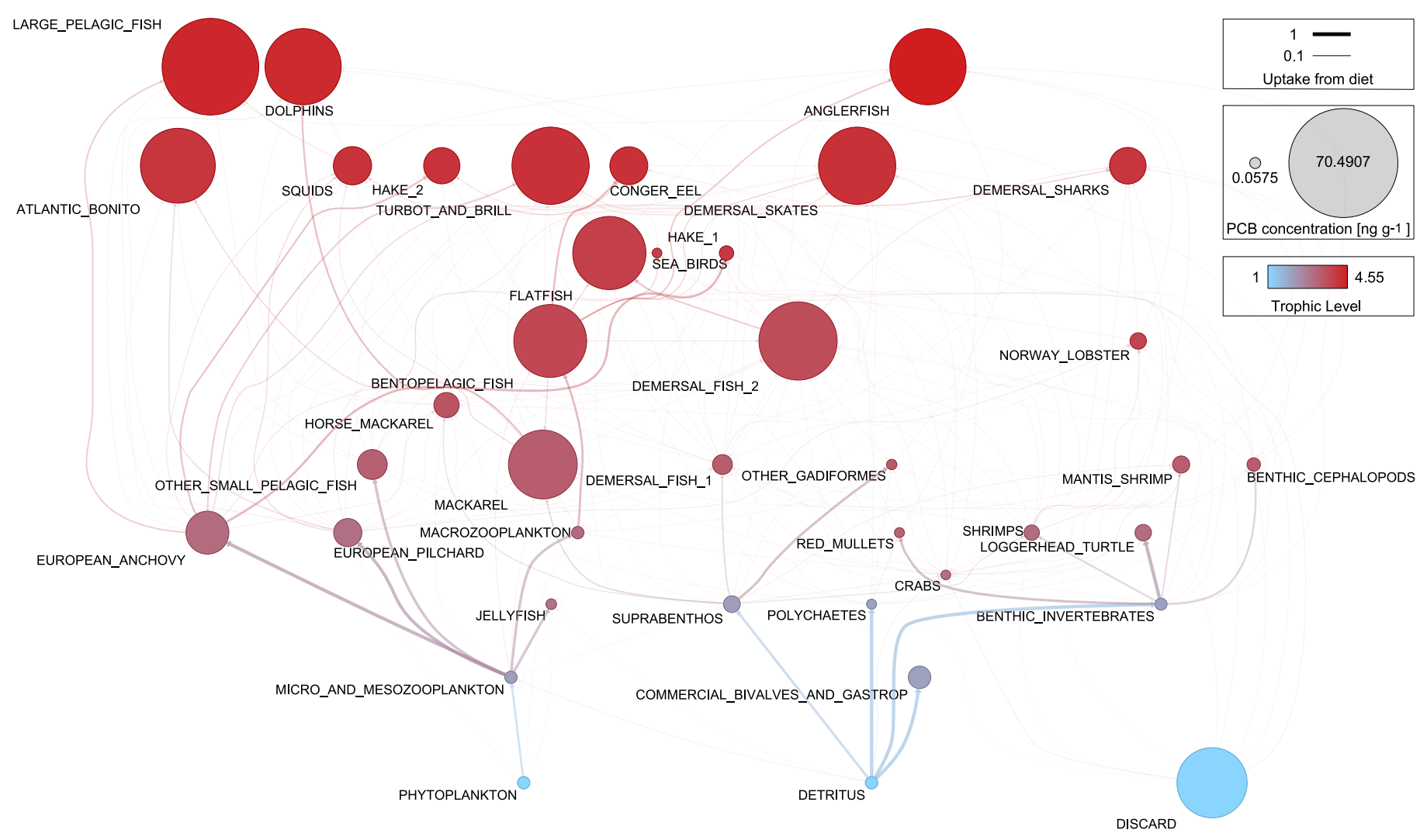

(b) Bioaccumulation network

Figure 3: Estimated Adriatic trophic (a) and PCBs bioaccumulation (b) networks. Nodes represent functional groups with size proportional to the biomass content (a) or PCBs concentration (b). Edges represent feeding connections with thickness proportional to the biomass (a) or contaminant (b) flow from the prey to the predator. Flows to detritus and to fishing discards are not shown. 
Table 4: Results of trophic and bioaccumulation networks estimation: $T L$, trophic level; $B$ biomass $\left(t \cdot \mathrm{km}^{-1}\right)$; PCBs concentration \pm standard deviation obtained with MCMC-based sampling $\left(\sum \mathrm{PCBs}, n g \cdot \mathrm{g}^{-1}\right) ; F\left(t \cdot n g \cdot \mathrm{y}^{-1} \cdot \mathrm{km}^{-2}\right)$ indicates PCBs outflows due to fishing, and Dis the fraction discarded. Keystoneness indices for the bioaccumulation model (highest values in bold) are $K S$, Keystoneness; $F B C$, Flow Betweenness Centrality; and $S C(i)$, Sensitivity Centrality at year $i$.

\begin{tabular}{|c|c|c|c|c|c|c|c|c|c|}
\hline Id.Group & $T L$ & $B$ & $\sum \mathrm{PCBs}$ & $F$ & Dis & $K S$ & $F B C$ & $S C(1)$ & $S C(2)$ \\
\hline 1.Phytoplankton & 1 & 16.658 & $2.247 \pm 0.955$ & 0 & 0 & -1.394 & 0 & 0.001 & 0.001 \\
\hline 2.Micro and mesozoop. & 2.05 & 9.512 & $2.247 \pm 0.955$ & 0 & 0 & 0.673 & 557.983 & 0.024 & 0.024 \\
\hline 3.Macrozoop. & 3.05 & 0.54 & $2.247 \pm 0.955$ & 0 & 0 & -3.479 & 11.474 & 0.005 & 3.891 \\
\hline 4.Jellyfish & 2.88 & 4 & $0.843 \pm 0.353$ & 0 & 0 & -0.296 & 0.331 & 0.001 & 0.001 \\
\hline 5.Suprabenthos & 2.11 & 1.01 & $5.952 \pm 3.247$ & 0 & 0 & -5.62 & 192.88 & 0.006 & 0.006 \\
\hline 6.Polychaetes & 2 & 9.984 & $0.348 \pm 0.2$ & 0 & 0 & -0.849 & 5.406 & 0 & 1.358 \\
\hline 7.Commercial benthic invert. & 2 & 0.043 & $10.502 \pm 5.369$ & 0.368 & 0 & -0.717 & 0 & 0.01 & 0.01 \\
\hline 8.Benthic Invert. & 2 & 79.763 & $2.12 \pm 0.846$ & 0.696 & 0.696 & -1.475 & 38.462 & 0 & 3.899 \\
\hline 9.Shrimps & 3.02 & 0.68 & $4.746 \pm 2.752$ & 0.157 & 0.081 & -0.685 & 50.236 & 0.004 & 3.901 \\
\hline 10.Norway lobster & 3.77 & 0.018 & $5.542 \pm 3.115$ & 0.205 & 0 & -0.751 & 6.257 & 0.005 & 3.902 \\
\hline 11.Mantis shrimp & 3.31 & 0.015 & $6.103 \pm 3.228$ & 0.439 & 0 & -2.043 & 1.515 & 0.006 & 0.006 \\
\hline 12.Crabs & 3.00 & 0.009 & $0.058 \pm 0.039$ & 0.01 & 0.01 & -3.119 & 75.123 & 0 & 0.224 \\
\hline 13.Benthic cephal. & 3.31 & 0.068 & $3.198 \pm 1.77$ & 0.499 & 0.006 & -1.28 & 16.473 & 0.003 & 3.899 \\
\hline 14.Squids & 4.14 & 0.02 & $23.289 \pm 8.172$ & 0.955 & 0 & -2.519 & 34.117 & 0.022 & 0.022 \\
\hline 15.Hake 1 & 4.00 & 0.06 & $3.852 \pm 0.617$ & 0.705 & 0.27 & -2.805 & 14.277 & 0.004 & 3.9 \\
\hline 16. Hake 2 & 4.11 & 0.56 & $21.658 \pm 5.95$ & 0 & 0 & -2.676 & 2.914 & 0.017 & 0.02 \\
\hline 17.Other gadiformes & 3.37 & 0.029 & $0.567 \pm 0.285$ & 0.061 & 0.047 & -2.664 & 2.186 & 0.001 & 2.211 \\
\hline 18.Red mullets & 3.19 & 0.025 & $0.385 \pm 0.262$ & 0.043 & 0 & -2.652 & 0.917 & 0 & 1.5 \\
\hline 19.Conger eel & 4.16 & 0.005 & $22.879 \pm 0.443$ & 0.183 & 0.183 & -0.261 & 5.791 & 0.022 & 3.919 \\
\hline 20.Anglerfish & 4.55 & 0.006 & $53.808 \pm 29.234$ & 0.377 & 0 & -3.176 & 0.395 & 0.051 & 0.052 \\
\hline 21.Flatfish & 3.89 & 0.009 & $51.436 \pm 30.137$ & 2.057 & 0 & -1.643 & 16.564 & 0.049 & 3.946 \\
\hline 22. Turbot and brill & 4.15 & 0.04 & $54.746 \pm 28.303$ & 0.876 & 0 & -3.803 & 19.136 & 0.052 & 3.95 \\
\hline 23.Demersal sharks & 4.09 & 0.018 & $21.84 \pm 11.571$ & 0.175 & 0 & -3.309 & 0.224 & 0.021 & 0.021 \\
\hline 24.Demersal skates & 4.15 & 0.003 & $54.833 \pm 29.337$ & 0.11 & 0 & -1.788 & 0.073 & 0.052 & 0.053 \\
\hline 25.Demersal fish 1 & 3.32 & 0.056 & $8.159 \pm 1.132$ & 0.865 & 0.416 & -1.15 & 135.968 & 0.008 & 3.904 \\
\hline 26.Demersal fish 2 & 3.62 & 0.24 & $55.424 \pm 28.667$ & 0.942 & 0.055 & -0.258 & 96.253 & 0.052 & 3.95 \\
\hline 27.Bentopelagic fish & 3.73 & 1.2 & $51.324 \pm 28.892$ & 0.103 & 0 & -1.108 & 40.106 & 0.049 & 3.946 \\
\hline 28.European Anchovy & 3.05 & 1.497 & $27.104 \pm 18.17$ & 13.579 & 0.136 & -2.038 & 19.736 & 0.025 & 3.922 \\
\hline 29.European Pilchard & 2.97 & 2.985 & $14.969 \pm 6.234$ & 6.077 & 0.629 & -0.764 & 3.809 & 0.014 & 3.911 \\
\hline 30.Small Pelagic Fish & 3.25 & 1.517 & $16.533 \pm 8.18$ & 0.215 & 0.017 & -2.124 & 3.231 & 0.016 & 3.913 \\
\hline 31.Horse Mackarel & 3.49 & 2.455 & $12.496 \pm 1.171$ & 0.275 & 0.025 & 0.157 & 14.643 & 0.012 & 3.909 \\
\hline 32.Mackarel & 3.32 & 1.683 & $47.96 \pm 21.422$ & 1.199 & 0.384 & -0.586 & 32.264 & 0.045 & 3.943 \\
\hline 33.Atlantic bonito & 4.09 & 0.3 & $52.704 \pm 29.504$ & 0.949 & 0 & -1.075 & 0.076 & 0.05 & 0.051 \\
\hline 34.Large Pelagic Fish & 4.34 & 0.138 & $70.491 \pm 20.461$ & 1.833 & 0 & -1.804 & 0.144 & 0.058 & 0.067 \\
\hline 35.Dolphins & 4.30 & 0.012 & $54.048 \pm 29.286$ & 0.005 & 0.005 & -1.276 & 13.609 & 0.052 & 3.949 \\
\hline 36.Loggerhead turtle & 3.01 & 0.032 & $5.478 \pm 4.412$ & 0.022 & 0.022 & -0.816 & 0.423 & 0.005 & 0.005 \\
\hline 37.Sea birds & 3.90 & 0.001 & $0.161 \pm 0.058$ & 0 & 0 & -1.211 & 0.067 & 0 & 0 \\
\hline 38.Discard & 1 & 0.733 & $49.005 \pm 0.84$ & 0 & 0 & & & & \\
\hline 39.Detritus & 1 & 200 & $2.247 \pm 0.955$ & 0 & 0 & & & & \\
\hline
\end{tabular}




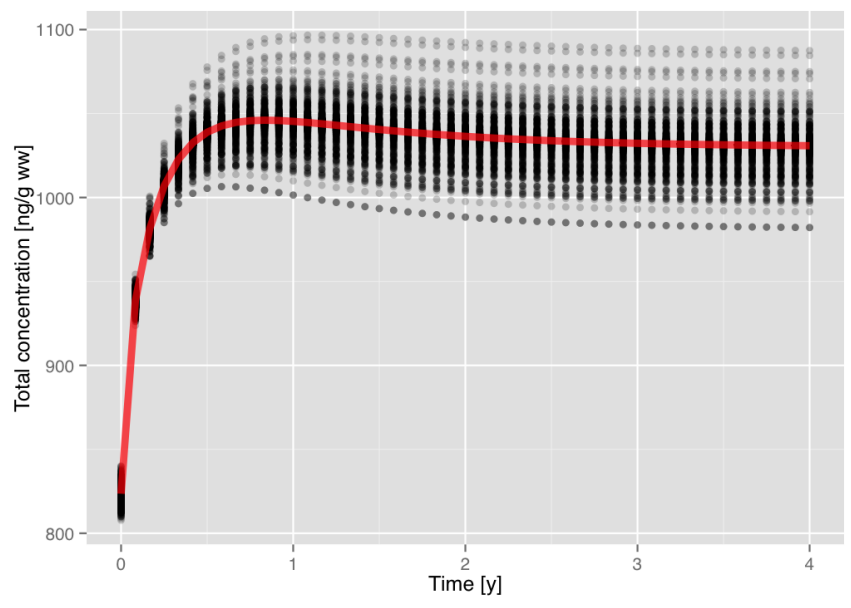

Figure 4: Temporal evolution of total PCBs concentrations, simulated through the dynamic ODE model over a period of 4 years and time step of 1 month (red line). Shaded dots indicate the results obtained after random perturbations of the initial concentration (100 uniformly distributed values for each species).

bound of the considered input PCBs values. The effects are even more evident if comparing concentrations of groups belonging to the same species but subject to different fishing pressures: Hake $1(<40 \mathrm{~cm}$, vulnerable to fishing, $\mathrm{PCB}=3.852)$ and Hake 2 (> $40 \mathrm{~cm}$, not vulnerable, $\mathrm{PCB}=21.658$ ); or $D e$ mersal fish 1 (overexploited, $\mathrm{PCB}=8.159$ ) and Demersal fish 2 $(\mathrm{PCB}=55.424)$.

Differently from natural detritus, the Discard group is characterized by a significant PCBs concentration. This mainly depends on its low biomass and on its species composition that, with their concentration, contributes to a considerable total inflow of contaminant to fishing discards (see Table 4, column Dis). Finally, with our bioaccumulation model we can estimate the PCBs concentration in the landing fraction of the biomass exported by fishing, computed as $\sum_{i} c_{i \rightarrow \text { Landing }} / \sum_{i} b_{i \rightarrow \text { Landing }}$. The mean concentration in landings is $18.17 \mathrm{ng} \cdot \mathrm{g}^{-1}$. This kind of analysis could provide an effective indicator of the chemical pollution in species of commercial interest.

\subsection{ODE bioaccumulation model}

We evaluate the long-term PCBs bioaccumulation dynamics in the Adriatic food web by simulating the ODE model (Eq. A.4). Figure 4 shows the results obtained under random perturbations of the initial concentration values taken from the static bioaccumulation network. We observe that the total PCBs concentration has a steep increase before reaching a plateau in the second year of the simulation. This is explained by the fact that groups in rapid equilibrium with the water phase (planktonic and detritus groups) are not mass-balanced in the bioaccumulation network. We notice that, in order to support the correctness and the applicability of the Sensitivity Centrality index (see Sect. 2.5), the qualitative dynamics of the system are relatively robust with respect to changes in the initial conditions.

\subsection{Keystoneness analysis}

The four networks plotted in Figure 5 show the centrality of species according to the indices of toxic keystoneness considered: $S C(1)$ Sensitivity Centrality, year 1; $S C(2)$ Sensitivity Centrality, year 2; $K S$ Libralato's keystoneness; and $F B C$ Flow Betweenness Centrality. Numerical results are reported in Table 4. Both $\mathrm{KS}$ and FBC identify the group Micro and mesozooplankton (id 2) as keystone, which is however not relevant for SC(1) and SC(2). According to SC(1), Large pelagic fish (34) is the most important group, but is low ranked by the other indices. This group also shows the highest estimated PCBs value. The highest SC(2) value is registered in both Turbot and brill (22) and Demersal fish 2 (26). Remarkably, the latter occupies important positions also in other indices: 3rd in $\mathrm{KS}$ and $\mathrm{SC}(1)$, 4th in FBC. As evidenced in Fig. 5 (c), FBC assigns a disproportionate centrality value (557.983) to its keystone. On the contrary, differences in KS (plot d) are less evident among groups since the index is computed with a logarithmic operation (see Sect. 2.5.1). In the evaluation of SC(1) (plot a), two clusters of species can be distinguished: one with higher values ranging in the interval [0.045, 0.058], and the other one with $S C(1) \in[0,0.025]$. The groups in the first cluster are (in decreasing order of importance): 34, 35, 26, 24, 22, 20, 33, 21, 27 and 32. They occupy high trophic positions ( $T L \in[3.31,4.55])$ and have initial PCBs concentrations ranging between 47.96 and $70.49 n g \cdot g^{-1} . S C(2)$ (plot b) performs in a similar way, identifying a larger set of important groups with values between 3.891 and 3.95, and with minor differences among species scores. Despite there are changes in species classification between $\mathrm{SC}(1)$ and $\mathrm{SC}(2)$, groups 21 , $22,26,27,32$ and 35 maintain top centrality positions in both rankings.

Comparison by extinction simulation. The comparison of Sensitivity Centrality with the other indices of keystoneness has been carried out by simulating the effects of successive extinctions on global network properties, performed by following the different rankings. Ideally, an effective index would identify the set of species that, when removed, produce strong perturbations at the global ecosystem level. Figure 6 illustrates the results on the total system throughflow (TST), i.e. the sum of contaminant flows; link density $(L D)$, the average number of links per group; and the average path length $(A P L)$, a measure of network robustness telling the average number of groups that each inflow passes through.

In our analysis, a good index of toxic keystoneness should lead to a rapid breakdown in TST, since low values imply a low total rate of contaminant transfer. We observe that extinctions performed following the rankings of SC(1) and SC(2) have the highest impact, thus indicating that SC gives an effective measure of importance as regards the total activity of the network. In particular, they halve the value of TST even before the first 10 extinctions, which is instead obtained only after 17 extinctions for $\mathrm{KS}$ and $\mathrm{FBC}$.

Similarly, the extinction of toxic keystones should yield decreased values of LD, since species with many trophic links have potentially a pivotal role in the contaminant transfer 


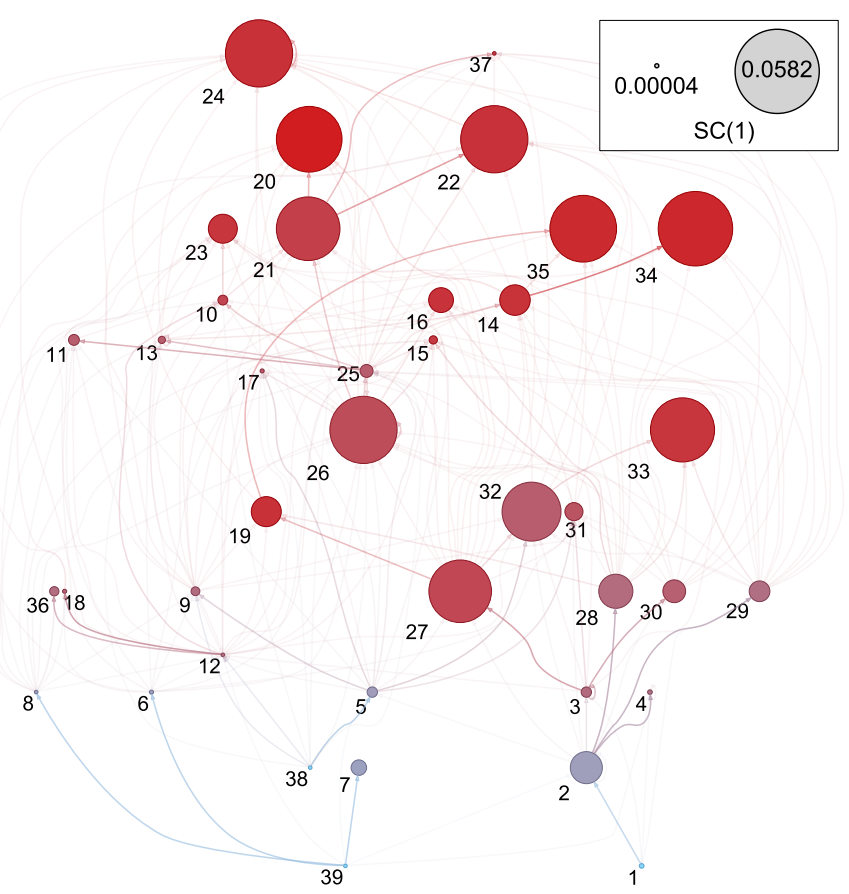

(a) Sensitivity Centrality, year $1(S C(1))$

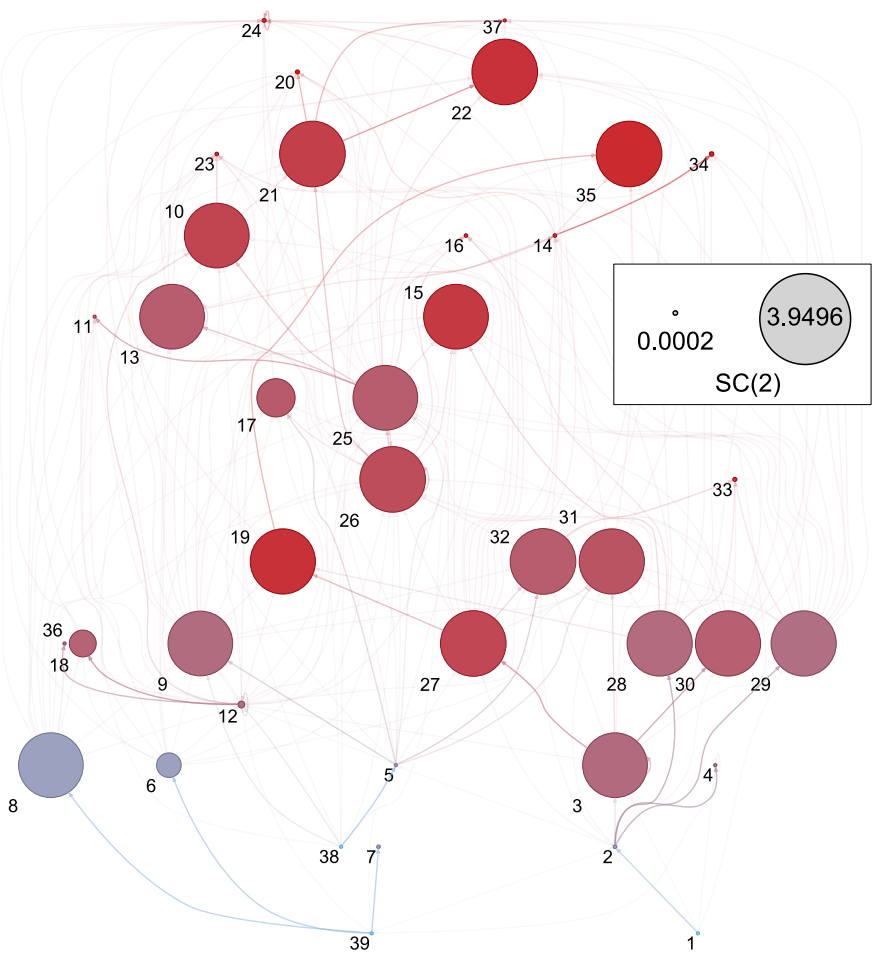

(b) Sensitivity Centrality, year $2(S C(2))$

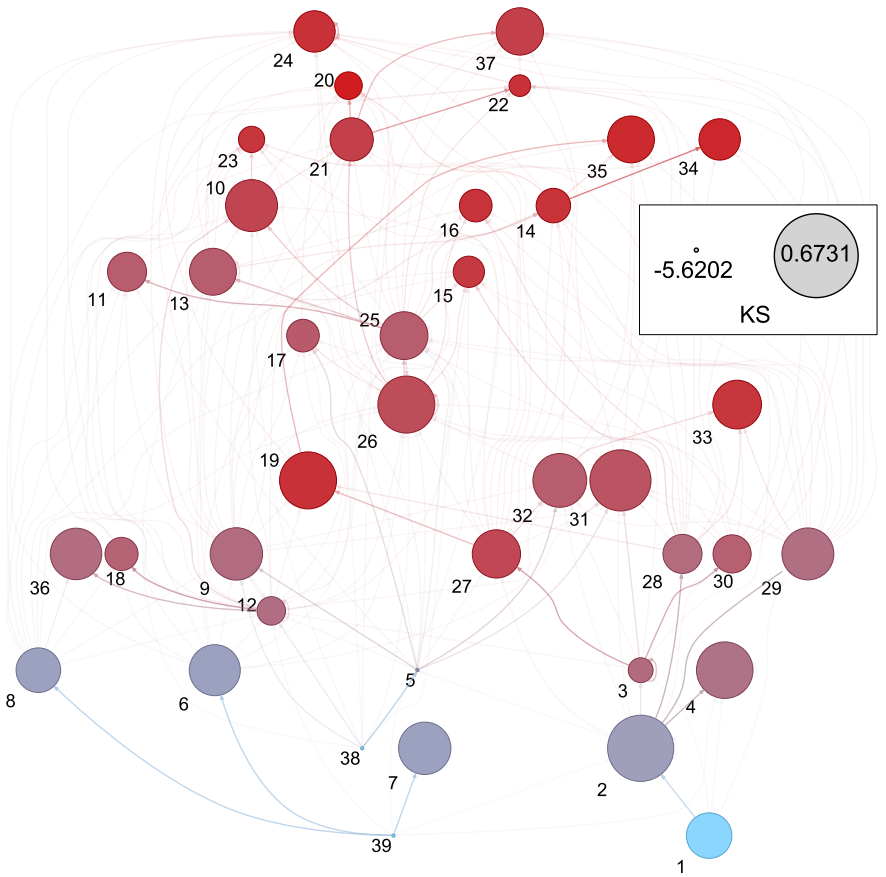

(c) Libralato's keystoneness $(K S)$

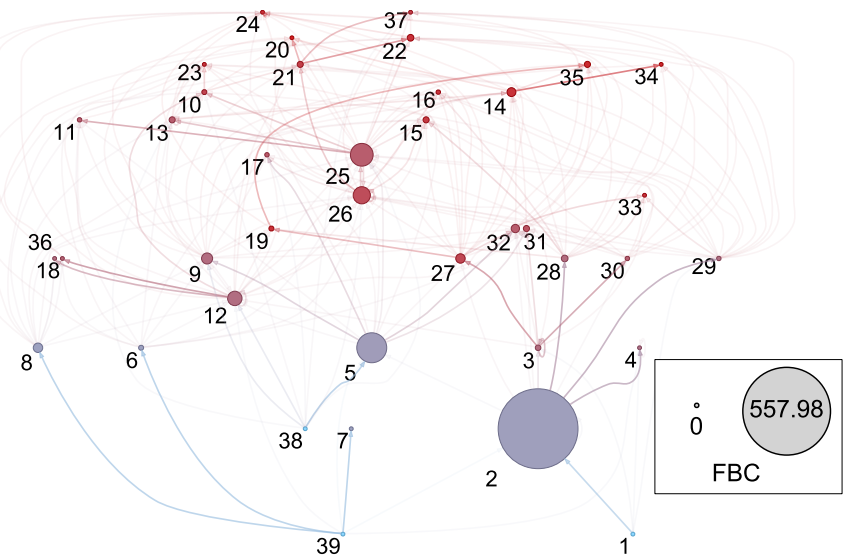

(d) Flow Betweenness Centrality ( $F B C$ )

Figure 5: Ranking of species in the Adriatic bioaccumulation model according to $S C(1)$ (a), $S C(2)$ (b), $K S$ (c) and $F B C$ (d). In the network plots, node size is proportional to the relative importance of species given by the corresponding indices. Node colour represents the trophic level as in Fig. 3 (b). 


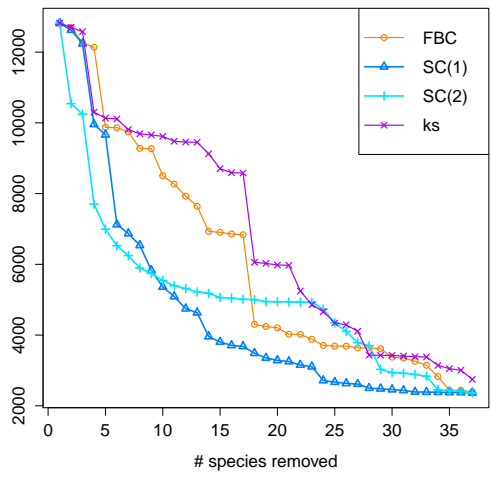

(a) Total System Throughflow (TST)

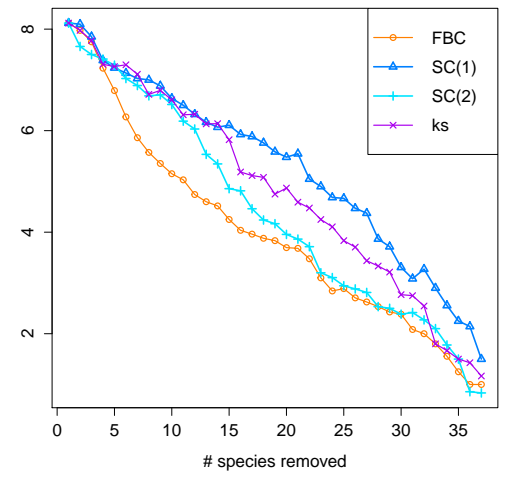

(b) Link Density $(L D)$

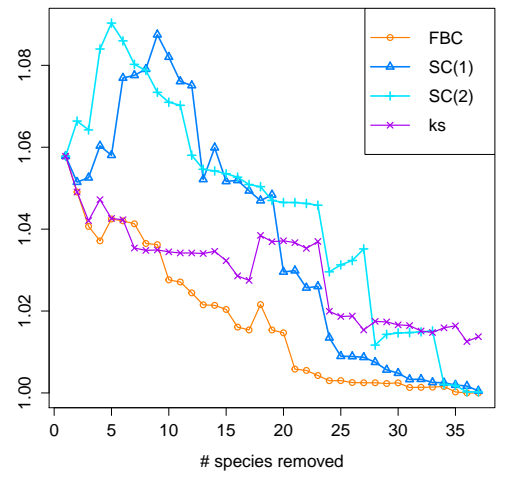

(c) Average Path Length $(A P L)$

Figure 6: Simulation of the effects of extinctions on global network indices: $T S T$ (a) $\left(n g \cdot g^{-1} \cdot \mathrm{km}^{-2} \cdot \mathrm{y}^{-1}\right), L D$ (b), $A P L$ (c). Species are removed according to the ranking of toxic keystoneness (from the most important to the least) obtained by Flow Betweenness Centrality (FBC), orange line; Sensitivity Centrality at 1 and 2 years $(S C(1)$ and $S C(2))$, light and dark blue line, respectively; and Libralato's keystoneness $(K S)$, purple line.

through the food web. In this case, FBC shows the best overall performance, even if the first 3 extinctions according to the $\mathrm{SC}(2)$ ranking produce the strongest effect. The qualitative nature of LD explains the good performance of FBC, which is an index based on topological considerations.

APL measures the efficiency of contaminant transport pathways, that is the number of trophic links needed to transfer the contaminant between any pair of groups. Therefore after the extinction of a toxic keystone an increased value is expected. For this network property, $\mathrm{SC}(1)$ and $\mathrm{SC}(2)$ have the best performance suggesting that our Sensitivity Centrality is effective in identifying species that promote the overall efficiency of contaminant transfer.

\subsection{Implementation}

We implemented the computational framework in R software with following packages: LIM (van Oevelen et al., 2010), estimation of the trophic and bioaccumulation network; NetIndices (Kones et al., 2009), global network indices (TST, LD and $A P L)$ and trophic levels; enaR (Borrett and Lau, 2012), MTI analysis (required to compute $K S$ ); sna (Butts, 2008), $F B C$ estimation; and FME (Soetaert and Petzoldt, 2010), ODE simulations and sensitivity analysis. Network plots have been generated with Graphviz (Ellson et al., 2002).

\section{Conclusions}

Recent advances in the application of food web ecology to ecotoxicological research have highlighted the influence of contaminants on the ecosystem structure and functions, and improved the ability of models to predict bioaccumulation phenomena in aquatic food webs. Ideally, an integrated pipeline of methods and information ranging from the molecular to the ecological level can effectively support environmental decisionmaking with a more comprehensive understanding of contamination patterns in an ecosystem. In this context, the main contribution of this study is the combination of computational and network analysis tools to estimate bioaccumulation in contaminated food webs and to identify keystone species in contamination pathways. We reconstructed the first food web-based bioaccumulation model for the Adriatic sea, providing a stateof-the-art review of PCBs experimental concentration data in species. Further, we defined a novel index based on sensitivity analysis, Sensitivity Centrality, to analyse toxic keystoneness. Our estimations evidenced that species at higher trophic positions exhibit higher PCBs concentrations, thus suggesting the occurrence of biomagnification phenomena in the Adriatic food web. Finally, we showed that the newly introduced index is able to identify species that have a large impact on the total amount of contaminant flows and on the PCBs transfer efficiency through trophic pathways.

We believe that the concept of sensitivity gives a simple yet mathematically well-grounded characterization of toxic keystones and more generally, that the problem of identifying the key species in a contaminated ecosystem could be better addressed by using indices that incorporate both network-level and dynamic information. These kinds of analyses could be more meaningful than just evaluating concentrations on single species, and could reveal which are the bioindicators to monitor and control in a polluted ecosystem for both conservation and remediation purposes (Taffi et al., 2014). Likewise, clarifying species centrality in the contaminant transfer could help in predicting the temporal evolution of bioaccumulation under different scenarios of natural or anthropogenic perturbations.

\section{Acknowledgements}

This work has been supported by the RITMARE Flagship Project funded by the Italian Ministry of University and Research.

\section{References}

Allesina S, Pascual M. Googling food webs: can an eigenvector measure species' importance for coextinctions? PLoS computational biology $2009 ; 5(9)$ 
Arnot JA, Gobas FA. A review of bioconcentration factor (BCF) and bioaccumulation factor (BAF) assessments for organic chemicals in aquatic organisms. Environmental Reviews 2006;14(4):257-97.

Bauer B, Jordán F, Podani J. Node centrality indices in food webs: Rank orders versus distributions. Ecological Complexity 2010;7(4):471-7.

Bayarri S, Baldassarri LT, Iacovella N, Ferrara F, Domenico Ad. PCDDs, PCDFs, PCBs and DDE in edible marine species from the Adriatic Sea. Chemosphere 2001;43(4):601-10.

Bellucci LG, Frignani M, Paolucci D, Ravanelli M. Distribution of heavy metals in sediments of the Venice Lagoon: the role of the industrial area. Science of the Total Environment 2002;295(1):35-49.

Borrett S, Lau M. Vignette: enaR. 2012. URL: http://cran.r-project. org/web/packages/enaR/vignettes/enaR.pdf.

Brigolin D, Savenkoff C, Zucchetta M, Pranovi F, Franzoi P, Torricelli P, Pastres R. An inverse model for the analysis of the venice lagoon food web. Ecological Modelling 2011;222(14):2404-13.

Brun R, Reichert P, Künsch HR. Practical identifiability analysis of large environmental simulation models. Water Resources Research 2001;37(4):101530.

Butts CT. Social network analysis with sna. Journal of Statistical Software 2008;24(6):1-51.

Calamari D, Zuccato E, Castiglioni S, Bagnati R, Fanelli R. Strategic survey of therapeutic drugs in the rivers po and lambro in northern italy. Environmental Science \& Technology 2003;37(7):1241-8.

Campanelli A, Grilli F, Paschini E, Marini M. The influence of an exceptional Po River flood on the physical and chemical oceanographic properties of the Adriatic Sea. Dynamics of Atmospheres and Oceans 2011;52(1):284-97.

Carrer S, Halling-Sørensen B, Bendoricchio G. Modelling the fate of dioxins in a trophic network by coupling an ecotoxicological and an ecopath model. Ecological Modelling 2000;126(2):201-23.

Christensen V, Walters C. Ecopath with Ecosim: methods, capabilities and limitations. Ecological modelling 2004;172(2):109-39.

Ciavatta S, Lovato T, Ratto M, Pastres R. Global uncertainty and sensitivity analysis of a food-web bioaccumulation model. Environmental Toxicology and Chemistry 2009;28(4):718-32.

Coll M, Piroddi C, Steenbeek J, Kaschner K, Lasram FBR, Aguzzi J, Ballesteros E, Bianchi CN, Corbera J, Dailianis T, et al. The biodiversity of the mediterranean sea: estimates, patterns, and threats. PloS one 2010;5(8): 11842

Coll M, Santojanni A, Palomera I, Arneri E, et al. Food-web changes in the adriatic sea over the last three decades. Marine Ecology Progress Series 2009;381:17-37.

Coll M, Santojanni A, Palomera I, Tudela S, Arneri E. An ecological model of the Northern and Central Adriatic Sea: analysis of ecosystem structure and fishing impacts. Journal of Marine Systems 2007;67(1):119-54.

Corsolini S, Aurigi S, Focardi S. Presence of Polychlorobiphenyls (PCBs) and Coplanar Congeners in the Tissues of the Mediterranean Loggerhead Turtle Caretta caretta. Marine Pollution Bulletin 2000;40(11):952-60.

Dalla Valle M, Codato E, Marcomini A. Climate change influence on pops distribution and fate: A case study. Chemosphere 2007;67(7):1287-95.

Dalla Valle M, Marcomini A, Jones KC, Sweetman AJ. Reconstruction of historical trends of pcdd/fs and pcbs in the venice lagoon, italy. Environment international 2005;31(7):1047-52.

De Laender F, Van Oevelen D, Middelburg J, Soetaert K. Uncertainties in ecological, chemical and physiological parameters of a bioaccumulation model: Implications for internal concentrations and tissue based risk quotients. Ecotoxicology and environmental safety 2010;73(3):240-6.

Degobbis D, Precali R, Ivancic I, Smodlaka N, Fuks D, Kveder S. Long-term changes in the northern adriatic ecosystem related to anthropogenic eutrophication. International Journal of Environment and Pollution 2000;13(1):495533.

Ellson J, Gansner E, Koutsofios L, North SC, Woodhull G. GraphvizâĂŤopen source graph drawing tools. In: Graph Drawing. Springer; 2002. p. 483-4.

Estrada E. Characterization of topological keystone species: local, global and "meso-scale" centralities in food webs. Ecological Complexity 2007;4(1):48-57.

Freeman LC, Borgatti SP, White DR. Centrality in valued graphs: A measure of betweenness based on network flow. Social networks 1991;13(2):141-54.

Hendriks AJ, van der Linde A, Cornelissen G, Sijm DT. The power of size. 1. Rate constants and equilibrium ratios for accumulation of organic substances related to octanol-water partition ratio and species weight. Environmental toxicology and chemistry 2001;20(7):1399-420.

Horvat M, Covelli S, Faganeli J, Logar M, Mandić V, Rajar R, Širca A, Žagar D. Mercury in contaminated coastal environments; a case study: the Gulf of Trieste. Science of the Total Environment 1999;237:43-56.

Jordán F. Keystone species and food webs. Philosophical Transactions of the Royal Society B: Biological Sciences 2009;364(1524):1733-41.

Kannan K, Corsolini S, Falandysz J, Oehme G, Focardi S, Giesy JP. Perfluorooctanesulfonate and related fluorinated hydrocarbons in marine mammals, fishes, and birds from coasts of the Baltic and the Mediterranean Seas. Environmental Science \& Technology 2002;36(15):3210-6.

Kelly BC, Ikonomou MG, Blair JD, Morin AE, Gobas FA. Food web-specific biomagnification of persistent organic pollutants. science 2007;317(5835):236-9.

Kones JK, Soetaert K, van Oevelen D, Owino JO. Are network indices robust indicators of food web functioning? a monte carlo approach. Ecological Modelling 2009;220(3):370-82.

Laender FD, Oevelen DV, Middelburg JJ, Soetaert K. Incorporating ecological data and associated uncertainty in bioaccumulation modeling: methodology development and case study. Environmental science \& technology 2009;43(7):2620-6.

Lamon L, MacLeod M, Marcomini A, Hungerbühler K. Modeling the influence of climate change on the mass balance of polychlorinated biphenyls in the adriatic sea. Chemosphere 2012;87(9):1045-51.

Libralato S, Christensen V, Pauly D. A method for identifying keystone species in food web models. Ecological Modelling 2006;195(3):153-71.

Lohmann R, Breivik K, Dachs J, Muir D. Global fate of POPs: current and future research directions. Environmental Pollution 2007;150(1):150-65.

Losso C, Ghirardini AV. Overview of ecotoxicological studies performed in the venice lagoon (italy). Environment international 2010;36(1):92-121.

Mackay D, Fraser A. Bioaccumulation of persistent organic chemicals: mechanisms and models. Environmental Pollution 2000;110(3):375-91.

Marcotrigiano G, Storelli M. Heavy metal, polychlorinated biphenyl and organochlorine pesticide residues in marine organisms: risk evaluation for consumers. Veterinary research communications 2003;27(1):183-95.

Marini M, Betti M, Grati F, Marconi V, Mastrogiacomo AR, Polidori P, Sanxhaku M. Evaluation of lindane diffusion along the southeastern Adriatic coastal strip (Mediterranean Sea): A case study in an Albanian industrial area. Marine pollution bulletin 2012;64(3):472-8

Marini M, Fornasiero P, Artegiani A. Variations of hydrochemical features in the coastal waters of monte conero: 1982-1990. Marine ecology 2002;23(s1):258-71

Marini M, Grilli F, Guarnieri A, Jones BH, Klajic Z, Pinardi N, Sanxhaku M. Is the southeastern Adriatic Sea coastal strip an eutrophic area? Estuarine, Coastal and Shelf Science 2010;88(3):395-406.

van Oevelen D, Van den Meersche K, Meysman F, Soetaert K, Middelburg J, Vézina A. Quantifying food web flows using linear inverse models. Ecosystems 2010;13(1):32-45.

Van der Oost R, Beyer J, Vermeulen NP. Fish bioaccumulation and biomarkers in environmental risk assessment: a review. Environmental toxicology and pharmacology 2003;13(2):57-149.

Penna N, Capellacci S, Ricci F. The influence of the po river discharge on phytoplankton bloom dynamics along the coastline of pesaro (italy) in the adriatic sea. Marine Pollution Bulletin 2004;48(3):321-6.

Perugini M, Cavaliere M, Giammarino A, Mazzone P, Olivieri V, Amorena M. Levels of polychlorinated biphenyls and organochlorine pesticides in some edible marine organisms from the Central Adriatic Sea. Chemosphere 2004;57(5):391-400

Picer M. Ddts and pcbs in the adriatic sea. Croat Chem Acta, Spec Issue 2000;73(1):123-86.

Power ME, Tilman D, Estes JA, Menge BA, Bond WJ, Mills LS, Daily G, Castilla JC, Lubchenco J, Paine RT. Challenges in the quest for keystones. BioScience 1996;46(8):609-20.

Rohr JR, Kerby JL, Sih A. Community ecology as a framework for predicting contaminant effects. Trends in Ecology \& Evolution 2006;21(11):606-13.

Russell RW, Gobas FA, Haffner GD. Role of chemical and ecological factors in trophic transfer of organic chemicals in aquatic food webs. Environmental Toxicology and Chemistry 1999;18(6):1250-7.

Ruus A, Ugland KI, Skaare JU. Influence of trophic position on organochlorine concentrations and compositional patterns in a marine food web. Environmental Toxicology and Chemistry 2002;21(11):2356-64.

Soetaert K, Petzoldt T. Inverse modelling, sensitivity and monte carlo analysis 
in $\mathrm{R}$ using package FME. Journal of Statistical Software 2010;33.

Spillman C, Hamilton DP, Hipsey MR, Imberger J. A spatially resolved model of seasonal variations in phytoplankton and clam (Tapes philippinarum) biomass in barbamarco lagoon, italy. Estuarine, Coastal and Shelf Science 2008;79(2):187-203.

Spillman C, Imberger J, Hamilton DP, Hipsey MR, Romero J. Modelling the effects of po river discharge, internal nutrient cycling and hydrodynamics on biogeochemistry of the northern adriatic sea. Journal of Marine Systems 2007;68(1):167-200.

Storelli M, Barone G, Garofalo R, Marcotrigiano G. Metals and organochlorine compounds in eel (Anguilla anguilla) from the Lesina lagoon, Adriatic Sea (Italy). Food Chemistry 2007a;100(4):1337-41.

Storelli M, Barone G, Marcotrigiano G. Polychlorinated biphenyls and other chlorinated organic contaminants in the tissues of Mediterranean loggerhead turtle Caretta caretta. Science of the Total Environment 2007b;373(2):45663.

Storelli M, Giacominelli-Stuffler R, Storelli A, Marcotrigiano G. Polychlorinated biphenyls in seafood: contamination levels and human dietary exposure. Food chemistry 2003;82(3):491-6.

Storelli M, Marcotrigiano G. Persistent organochlorine residues and toxic evaluation of polychlorinated biphenyls in sharks from the Mediterranean Sea (Italy). Marine pollution bulletin 2001;42(12):1323-9.

Taffi M, Paoletti N, Angione C, Pucciarelli S, Marini M, Lio P. Bioremediation in marine ecosystems: a computational study combining ecological modelling and flux balance analysis. Frontiers in Genetics 2014;5(319). URL: http://www.frontiersin.org/systems_biology/10.3389/ fgene.2014.00319/abstract. doi:10.3389/fgene.2014.00319.

Ulanowicz R, Puccia C. Mixed trophic impacts in ecosystems. Coenoses 1990;5(1):7-16.

Ulanowicz RE. Quantitative methods for ecological network analysis. Computational Biology and Chemistry 2004;28(5):321-39.

Vézina AF, Platt T. Food web dynamics in the ocean. 1. Best-estimates of flow networks using inverse methods. Marine ecology progress series 1988;42(3):269-87.

Walters DM, Fritz KM, Johnson BR, Lazorchak JM, McCormick FH. Influence of trophic position and spatial location on polychlorinated biphenyl (pcb) bioaccumulation in a stream food web. Environmental science \& technology 2008;42(7):2316-22.

Walters DM, Mills MA, Cade BS, Burkard LP. Trophic Magnification of PCBs and Its Relationship to the Octanol- Water Partition Coefficient. Environmental science \& technology 2011;45(9):3917-24.

\section{Appendix A. Supplementary Materials}

\section{Appendix A.1. Derivation of dynamic bioaccumulation ODEs}

We define a dynamic bioaccumulation model on top of a multi-species Lotka-Volterra system used to describe the temporal changes in species biomass. In its general form, the Lotka-Volterra system is formulated as:

$$
\dot{B}_{i}(t)=B_{i}(t)\left(g_{i}-\sum_{j} A_{i j} B_{j}(t)\right)
$$

where $B_{i}(t)$ is the biomass of species $i$ at time $t ; g_{i}$ is the intrinsic growth rate of $i$; and $A$ is the interaction matrix. In particular $A_{i j}$ describes the predation effect of species $j$ on species $i$. Parameters of the ODE model are derived from the estimated food web model:

- $B_{i}(0)=B_{i}$, initial biomass values are those in the static food web estimated with LIM;

- $g_{i}=\frac{\sum_{j} b_{j \rightarrow i}-\sum_{j} b_{i \rightarrow j}}{B_{i}(0)}$, with $j$ ranging among the external groups; the growth rate of $i$ is the sum of exogenous inflows and outflow, over the estimated biomass of $i$;
- $A_{i j}=\frac{b_{i \rightarrow j}-b_{j \rightarrow i}}{B_{i}(0) \cdot B_{j}(0)}$, the interaction rate between prey $i$ and predator $j$ is calculated as the net flow from $i$ to $j$ divided by the estimated biomasses of $i$ and $j$.

Additionally, we define the biomass flow rate from group $i$ to $j$ at time $t, b_{i \rightarrow j}(t)$, which is non-linear with respect to the biomasses of $i$ and $j$, as:

$$
b_{i \rightarrow j}(t)=\frac{b_{i \rightarrow j}}{B_{i}(0) \cdot B_{j}(0)} \cdot B_{i}(t) \cdot B_{j}(t)
$$

in such a way that Eq. A.1 can be rewritten as:

$$
\dot{B}_{i}(t)=g_{i} \cdot B_{i}(t)+\sum_{j} b_{j \rightarrow i}(t)-\sum_{j} b_{i \rightarrow j}(t)
$$

Therefore, the dynamics of the contaminant concentration in species $i, C_{i}(t)$, is given by the net sum of contaminant flows, over the biomass of $i$ :

$$
\begin{aligned}
& \dot{C}_{i}(t)=w_{i} \cdot C_{\text {water }}+ \\
& \frac{g_{i} \cdot B_{i}(t) \cdot C_{i}(t)+\sum_{j} b_{j \rightarrow i}(t) \cdot C_{j}(t)-\sum_{j} b_{i \rightarrow j}(t) \cdot C_{i}(t)}{B_{i}(t)}
\end{aligned}
$$

where $C_{\text {water }}$ is the concentration in water (assumed constant) and $w_{i}$ is the uptake rate from water by group $i$. As done for the biomass equations, the initial concentrations correspond to those estimated in the static bioaccumulation network: $C_{i}(0)=$ $C_{i}$, for each group $i$.

Finally, expanding the interaction terms, Eq. A.2 is equivalent to the following:

$$
\begin{aligned}
\dot{C}_{i}(t)=w_{i} \cdot C_{\text {water }}+ & g_{i} \cdot C_{i}(t)+\sum_{j}\left(\frac{b_{j \rightarrow i}}{B_{i}(0) \cdot B_{j}(0)} \cdot B_{j}(t) \cdot C_{j}(t)\right) \\
& -\sum_{j}\left(\frac{b_{i \rightarrow j}}{B_{i}(0) \cdot B_{j}(0)} \cdot B_{j}(t) \cdot C_{i}(t)\right) \quad(\mathrm{A} .3)
\end{aligned}
$$

We focus on the temporal changes in concentrations independent of the biomass variations, thus assuming constant species biomass $\left(B_{i}(t)=B_{i}(0), \forall t\right)$, which gives the following system of linear differential equations:

$$
\dot{C}_{i}(t)=w_{i} \cdot C_{\text {water }}+g_{i} \cdot C_{i}(t)+\sum_{j}\left(\frac{b_{j \rightarrow i} \cdot C_{j}(t)-b_{i \rightarrow j} \cdot C_{i}(t)}{B_{i}(0)}\right)
$$

Note that this simplification does not change the quantitative dynamics of the model, because biomasses have been estimated under mass-balance conditions. 
Table A.5: Input data for the estimation of the trophic newtork from (Coll et al., 2007). B, biomass $\left(t \cdot k m^{-2}\right) ; P$, production rate $\left(y r^{-1}\right) ; Q$, consumption rate $\left(y r^{-1}\right)$; Lan, landed fraction of biomass exported by fishing $\left(t \cdot \mathrm{km}^{-2} \cdot \mathrm{yr}^{-1}\right)$, and $\mathrm{Dis}$ the fraction discarded $\left(t \cdot \mathrm{km}^{-2} \cdot \mathrm{yr}^{-1}\right)$.

\begin{tabular}{|c|c|c|c|c|c|}
\hline Id.Group & $B$ & $P$ & $Q$ & Lan & Dis \\
\hline 1.Phytoplankton & 16.658 & 69.03 & & & \\
\hline 2.Micro and mesozooplankton & 9.512 & 30.43 & 49.87 & & \\
\hline 3.Macrozooplankton & 0.54 & 21.28 & 53.14 & & \\
\hline 4.Jellyfish & 4 & 14.6 & 50.48 & & \\
\hline 5.Suprabenthos & 1.01 & 8.4 & 54.36 & & \\
\hline 6.Polychaetes & 9.984 & 1.9 & 11.53 & & \\
\hline 7.Commercial benthic invertebrates & 0.043 & 1.06 & 3.13 & 0.035 & \\
\hline 8.Benthic Invertebrates & 79.763 & 1.06 & 3.13 & & 0.328 \\
\hline 9.Shrimps & & 3.21 & 7.2 & 0.016 & 0.017 \\
\hline 10.Norway lobster & 0.018 & 1.25 & 4.56 & 0.037 & \\
\hline 11.Mantis shrimp & 0.015 & 1.5 & 4.56 & 0.072 & \\
\hline 12.Crabs & 0.009 & 2.44 & 4.73 & 0.002 & 0.177 \\
\hline 13.Benthic cephalopods & 0.068 & 2.96 & 5.3 & 0.154 & 0.002 \\
\hline 14.Squids & 0.02 & 3.11 & 26.47 & 0.041 & \\
\hline 15.Hake 1 & 0.06 & 1 & 4.24 & 0.113 & 0.07 \\
\hline 16.Hake 2 & & 0.5 & 1.85 & & \\
\hline 17.Other gadiformes & 0.029 & 1.59 & 4.37 & 0.025 & 0.083 \\
\hline 18.Red mullets & 0.025 & 1.9 & 8.02 & 0.112 & \\
\hline 19.Conger eel & 0.005 & 1.92 & 6.45 & & 0.008 \\
\hline 20.Anglerfish & 0.006 & 1.04 & 4.58 & 0.007 & \\
\hline 21.Flatfish & 0.009 & 1.43 & 9.83 & 0.04 & \\
\hline 22.Turbot and brill & & 1.43 & 5.34 & 0.016 & \\
\hline 23.Demersal sharks & 0.018 & 0.63 & 4.47 & 0.008 & \\
\hline 24.Demersal skates & 0.003 & 1.11 & 7.08 & 0.002 & \\
\hline 25.Demersal fish 1 & 0.056 & 2.4 & 7.68 & 0.055 & 0.051 \\
\hline 26.Demersal fish 2 & & 2.4 & 5.68 & 0.016 & 0.001 \\
\hline 27.Bentopelagic fish & & 1.07 & 7.99 & 0.002 & \\
\hline 28.European Anchovy & $1.019-6.611$ & 0.87 & 11.02 & 0.496 & 0.005 \\
\hline 29.European Pilchard & $2.985-7.803$ & 0.75 & 9.19 & 0.364 & 0.042 \\
\hline 30.Small Pelagic Fish & $0.413-1.517$ & 1.1 & 11.29 & 0.012 & 0.001 \\
\hline 31.Horse Mackarel & $0.659-2.455$ & 0.99 & 7.57 & 0.02 & 0.002 \\
\hline 32.Mackarel & $0.452-1.683$ & 0.99 & 6.09 & 0.017 & 0.008 \\
\hline 33.Atlantic bonito & 0.3 & 0.39 & 4.54 & 0.018 & \\
\hline 34.Large Pelagic Fish & 0.138 & 0.37 & 1.99 & 0.026 & \\
\hline 35.Dolphins & 0.012 & 0.08 & 11.01 & & 0.0001 \\
\hline 36.Loggerhead turtle & 0.032 & 0.17 & 2.54 & & 0.004 \\
\hline 37.Sea birds & 0.001 & 4.61 & 69.34 & & \\
\hline 38.Discard & 0.733 & & & & \\
\hline 39.Detritus & 200 & & & & \\
\hline
\end{tabular}




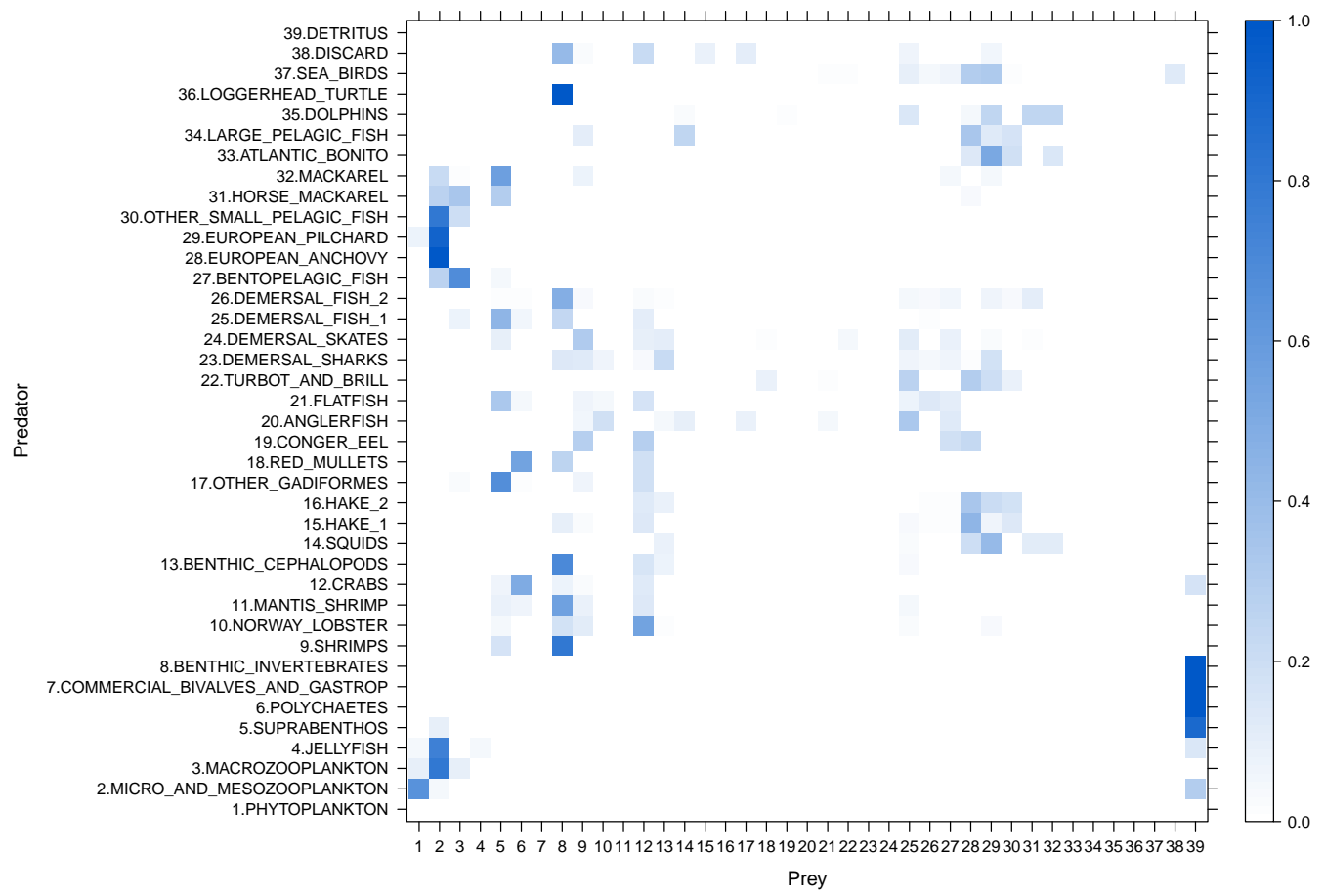

(a) Diet composition matrix

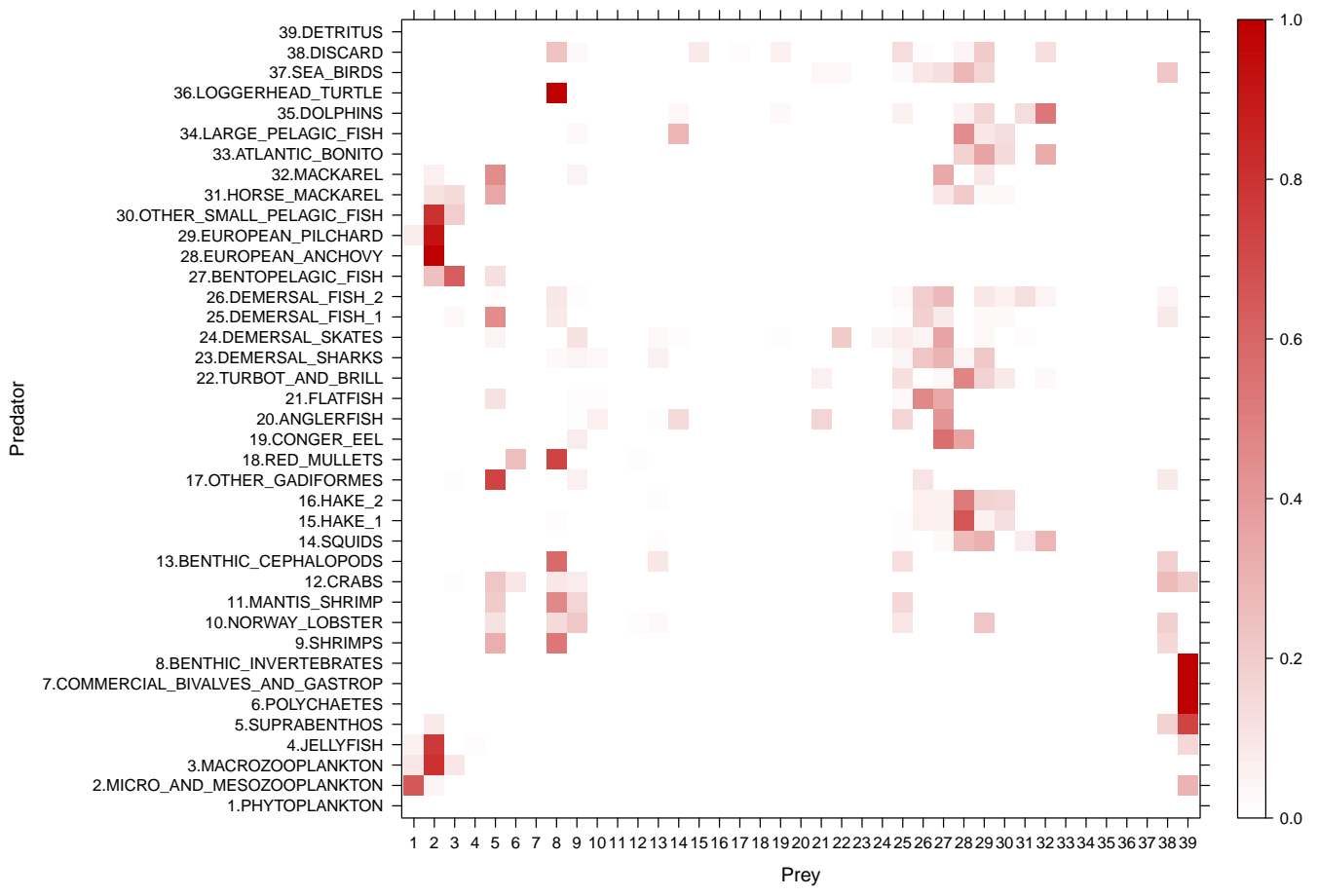

(b) Contaminant uptake from diet matrix

Figure A.7: Level plots of the diet composition matrix in the trophic network (a) and of the contaminant uptake rate from diet relative to the PCB bioaccumulation network. Darker cells indicate feeding links where the contribution of the prey in the diet/PCBs concentration of the predator is higher. Diet composition is taken from Coll et al. (2007), while the uptake rate of a predator $j$ from a prey $i, U_{i j}$, is the contaminant flow from $i$ to $j$ scaled by the sum of the inflows of $j$. 


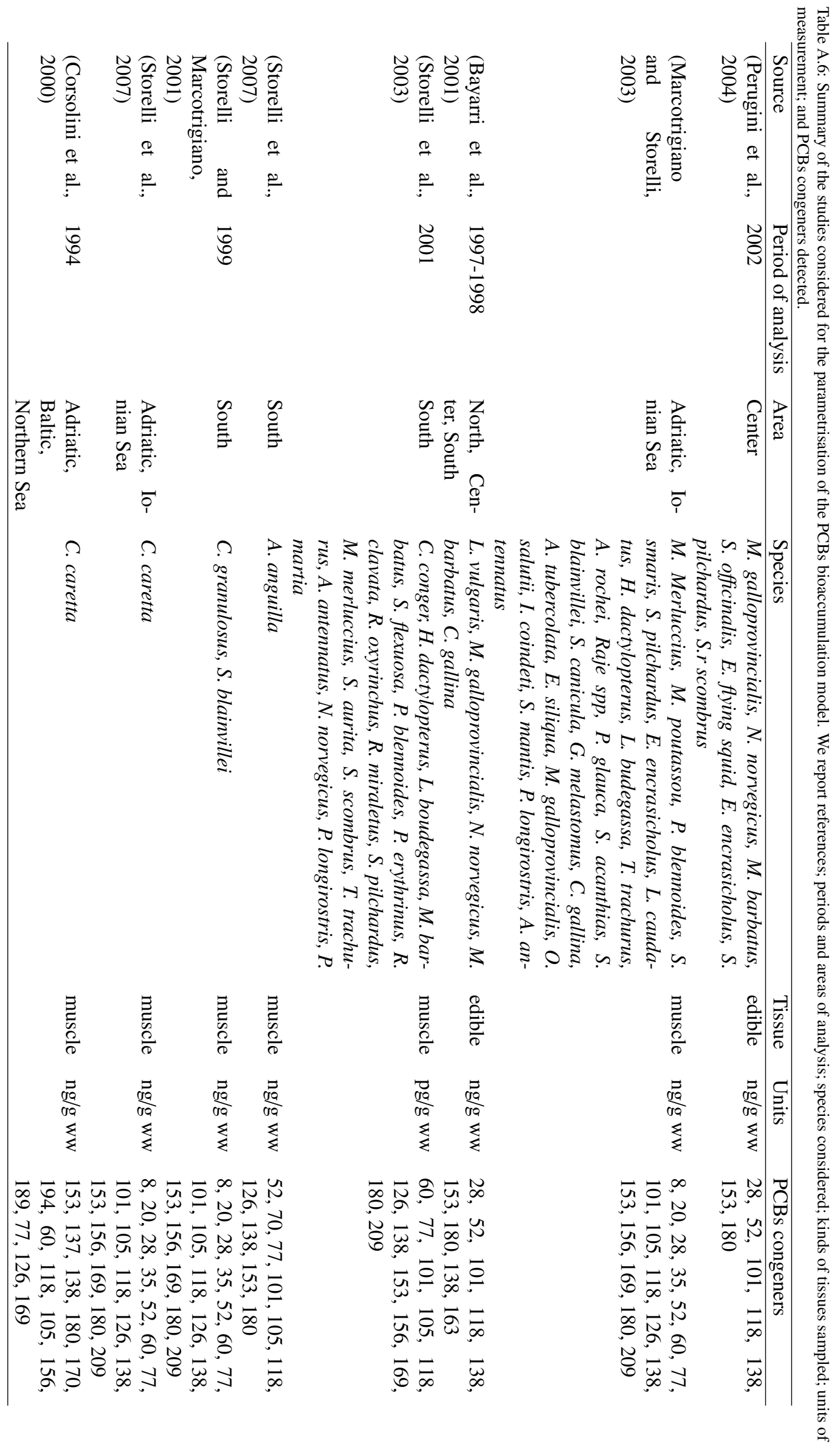

